\title{
Value of Information Analysis Project Gnome Site, New Mexico
}

\author{
prepared by \\ Greg Pohll and Jenny Chapman \\ submitted to \\ Stoller Corporation \\ Office of Legacy Management \\ U.S. Department of Energy \\ Grand Junction, Colorado
}

February 2010

Publication No. 45227 
Reference herein to any specific commercial product, process, or service by trade name, trademark, manufacturer, or otherwise, does not necessarily constitute or imply its endorsement, recommendation, or favoring by the United States Government or any agency thereof or its contractors or subcontractors.

Available for sale to the public from:

\author{
U.S. Department of Commerce \\ National Technical Information Service \\ 5285 Port Royal Road S/D \\ Springfield, VA 22161-0002 \\ Phone: 800.553 .6847 \\ Fax: 703.605.6900 \\ Email: orders@ntis.gov \\ Online ordering: http://www.osti.gov/ordering.htm
}

Available electronically at http://www.osti.gov/bridge

Available for a processing fee to the U.S. Department of Energy and its contractors, in paper, from:

U.S. Department of Energy

Office of Scientific and Technical Information

P.O. Box 62

Oak Ridge, TN 37831-0062

Phone: 865.576.8401

Fax: 865.576.5728

Email: reports@adonis.osti.gov 
DOE/NV/26383-07

LMS/GNO/S04740

\title{
Value of Information Analysis Project Gnome Site, New Mexico
}

\author{
prepared by \\ Greg Pohll and Jenny Chapman \\ Division of Hydrologic Sciences \\ Desert Research Institute \\ Nevada Division of Higher Education
}

Publication No. 45227

\author{
Submitted to \\ Stoller Corporation \\ Office of Legacy Management \\ U.S. Department of Energy \\ Grand Junction, Colorado
}

February 2010

The work upon which this report is based was supported by the U.S. Department of Energy under Contract \#DE-AC52-06NA26383 and Prime DOE Contract \#DE-AC01-02GJ79491. Approved for public release; further dissemination unlimited. 
THIS PAGE INTENTIONALLY LEFT BLANK 


\section{EXECUTIVE SUMMARY}

The Project Gnome site in southeastern New Mexico was the location of an underground nuclear detonation in 1961 and a hydrologic tracer test using radionuclides in 1963. The tracer test is recognized as having greater radionuclide migration potential than the nuclear test because the tracer test radionuclides (tritium, ${ }^{90} \mathrm{Sr},{ }^{131} \mathrm{I}$, and ${ }^{137} \mathrm{Cs}$ ) are in direct contact with the Culebra Dolomite aquifer, whereas the nuclear test is within a bedded salt formation. The tracer test is the topic here. Recognizing previous analyses of the fate of the Gnome tracer test contaminants (Pohll and Pohlmann, 1996; Pohlmann and Andricevic, 1994), and the existence of a large body of relevant investigations and analyses associated with the nearby Waste Isolation Pilot Plant (WIPP) site (summarized in US DOE, 2009), the Gnome Site Characterization Work Plan (U.S. DOE, 2002) called for a Data Decision Analysis to determine whether or not additional characterization data are needed prior to evaluating existing subsurface intrusion restrictions and determining long-term monitoring for the tracer test. Specifically, the Work Plan called for the analysis to weigh the potential reduction in uncertainty from additional data collection against the cost of such field efforts.

The cost-benefit analysis is implemented for the Gnome tracer test using a Bayesianstyle Value of Information Analysis (VOIA). System uncertainty is derived from a groundwater flow and transport model that transfers uncertainty in input parameters to uncertainty in the system (in this case, radionuclide migration) using a Monte Carlo analysis. The primary uncertainty of concern for estimating the volume of groundwater impacted by the Gnome tracer test is the unknown spatial distribution of hydraulic conductivity. Other sources of uncertainty in the flow and transport model are reasonably constrained by existing information, whereas work at the WIPP site has identified a very large range in hydraulic conductivity, and a complex spatial pattern, in the Culebra Dolomite. The economic costs considered include data collection costs, losses due to the contaminated water (the value of the water), and consequences of making improper decisions (litigation costs, regulatory fines, etc.).

The groundwater flow and transport model is based on a variety of hydrogeologic data collected at the Gnome site and the nearby WIPP site. The model domain was selected to take advantage of the hydraulic head data adjacent to the WIPP site and an assumed discharge point of the Culebra aquifer at the Pecos River. The domain was structured such that radionuclides introduced during the tracer test would migrate toward the boundary associated with the Pecos River. This southwest-directed flow is in contrast to the predominantly southerly flow depicted for the Culebra in WIPP models (Hart et al., 2009), and results from simplifications made for the VOIA based on data availability and the metric of concern (volume of affected groundwater).

Along with published data, a small-scale flow and transport model of the Gnome tracer test itself was used to help parameterize the VOIA model with respect to effective porosity, dispersivity, and matrix diffusion. Breakthrough curves observed during the tracer were used, as well as monitoring data from the intervening decades. This analysis revealed uncertainty in the amount of ${ }^{90} \mathrm{Sr}$ injected during the tracer test, with observed concentrations being consistent with a lower injected mass than the amount approved for purchase for the test or mentioned in informal field notes (record of the actual amount injected has not been found). Nonetheless, ${ }^{90} \mathrm{Sr}$ represents the contaminant most likely to yield concentrations above the drinking water standard downgradient of the tracer test, compared to the other 
injected tracers. As a result, the VOIA model simulates migration of ${ }^{90} \mathrm{Sr}$ over a 1,000 -year time period to evaluate uncertainty in contaminant transport.

Given an assumed cost of water in the Gnome area of $\$ 1.14$ per cubic meter, an assumed cost of failure of $\$ 22.80$ per cubic meter (this includes the value of the water to replace contaminated water, and costs for litigation and regulatory penalties), and assuming a 95-percent confidence level is used for decision making, the prior project costs are estimated to be $\$ 5,986,000$. Many different scenarios for collecting additional hydraulic conductivity data were considered, and their impact on model uncertainty calculated by updating the flow and transport analysis. The expected value of sample information in all cases was less than the cost to collect the data. From an economic viewpoint, additional characterization of hydraulic conductivity at Gnome is not recommended prior to evaluating subsurface restrictions and determining long-term monitoring.

Based on the VOIA, it is recommended that existing information be used as a basis for designing a site management and monitoring program, rather than embarking on site characterization. Though existing information can provide the initial basis, the design process should embrace iterative improvement as it is developed. In particular, the direction of groundwater flow remains a significant uncertainty for a detection-monitoring network (the VOIA analysis was insensitive to direction of flow, focusing instead on volume of affected groundwater). It is recommended that newly acquired information gathered from initial monitoring wells be used to iteratively update and improve contaminant migration forecasts and improve future well locations as the network is developed. 


\section{CONTENTS}

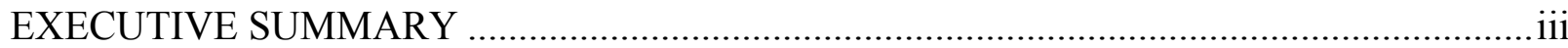

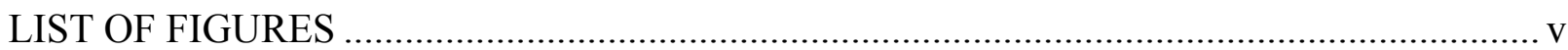

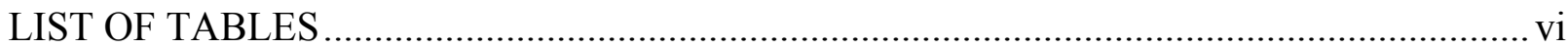

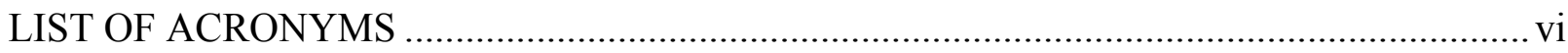

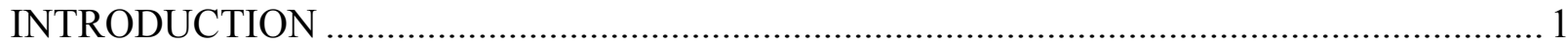

HYDROGEOLOGIC SETTING …......................................................................... 1

Gnome Tracer Test Description .................................................................................... 6

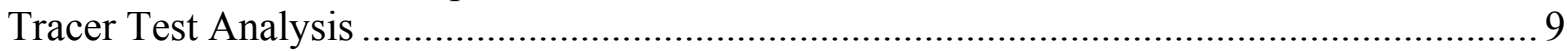

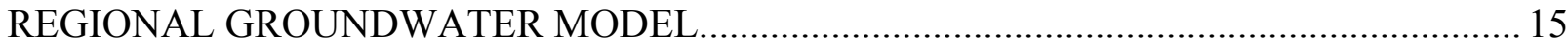

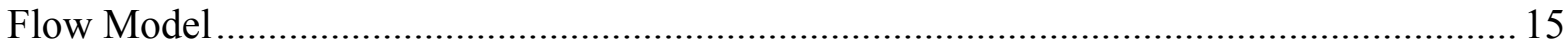

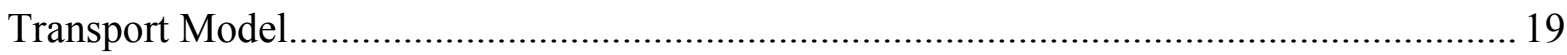

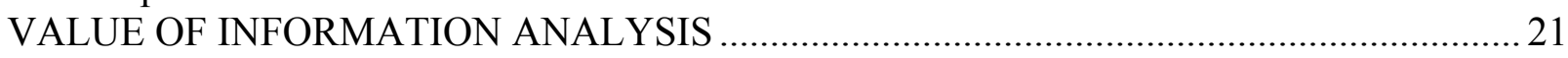

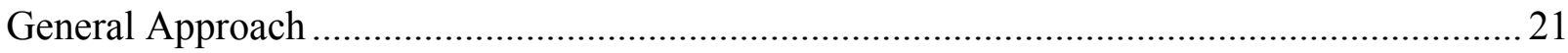

Analysis Framework ....................................................................................... 23

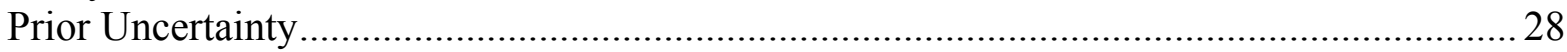

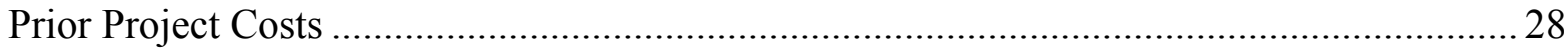

Value of Perfect Information ................................................................................... 31

Value of Sample Information................................................................................... 31

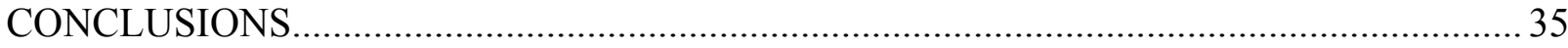

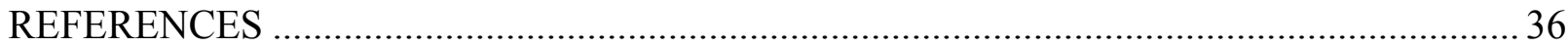

APPENDIX. COST ESTIMATES FOR FIELD ACTIVITIES ......................................... 41

\section{LIST OF FIGURES}

1. Project Gnome site located southeast of Carlsbad, including model domain

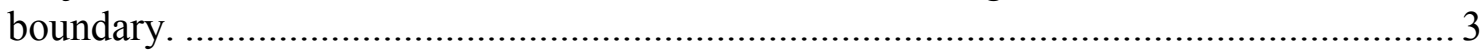

2. Cross section through the Project Gnome site showing the relation of nuclear cavity, drift, and shaft to local stratigraphy (modified from Gard, 1968). .................... 4

3. Example transmissivity zone map from Hart et al. (2009).........................................5

4. Measured hydraulic conductivity within the Culebra dolomite (data from Cauffman et al., 1990)........................................................................................ 7

5. Measured tritium activity for the two-well tracer test from Grove and Beetem (1971) and Wood (USGS, written communication, 1996) ..................................... 8

6. Groundwater model domain used in the tracer test analysis.................................... 10

7. Simulated and measured tritium concentrations at USGS-4 (a) during the tracer test, and (b) following the tracer test. ................................................................... 12

8. Simulated and measured tritium concentrations at USGS-8 following the tracer

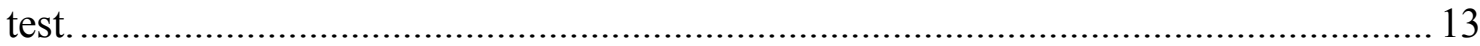

9. Simulated and measured 90Sr concentrations at (a) USGS-4 and (b) USGS-8.......... 14

10. Simulated and measured ${ }^{90} \mathrm{Sr}$ concentrations at USGS-4 (a), and USGS-8 (b) for various source injection masses and retardation values.

11. Location of head measurements used to define the specified head boundary with selected values of head measurements.

12. Single realization simulation of the hydraulic conductivity field.............................. 20 


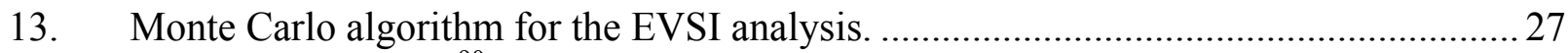

14. Probability map for ${ }^{90} \mathrm{Sr}$ contaminant plume (1,000-year simulation). ............................. 29

15. Relationship between selected level of confidence and total project costs for

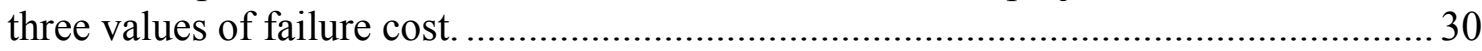

16. Histogram of expected project cost using 500 Monte Carlo realizations. ........................ 31

17. Locations of hydraulic conductivity sampling points for each scenario........................ 33

18. Calculated Expected Value of Sample Information (EVSI) in thousands of

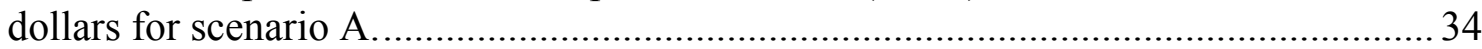

\section{LIST OF TABLES}

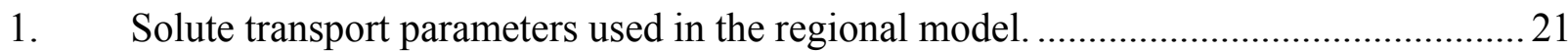

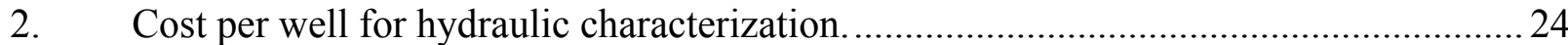

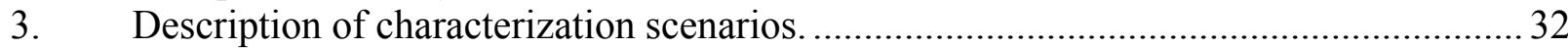

4. Expected value of sampling information for the characterization scenarios. ...................32

\section{LIST OF ACRONYMS}

DDA Data Decision Analysis

DRI Desert Research Institute

EVMI expected value of measurement information

EVPI expected value of perfect information

MCL maximum contaminant level

SGS sequential Gaussian simulation

SNJV Stoller-Navarro Joint Venture

USGS U.S. Geological Survey

VOIA value of information analysis

WIPP Waste Isolation Pilot Plant 


\section{INTRODUCTION}

The Project Gnome site in southeastern New Mexico was the location of an underground detonation of a 3-kiloton nuclear device in 1961 and a hydrologic tracer test using radionuclides in 1963 . The tracer test involved the injection of tritium, ${ }^{90} \mathrm{Sr},{ }^{131} \mathrm{I}$, fluorescein, and ${ }^{137} \mathrm{Cs}$ directly into the Culebra dolomite, a 10-m-thick aquifer located approximately $150 \mathrm{~m}$ below land surface. The Gnome nuclear test was conducted in the Salado Formation, a thick salt deposit located $200 \mathrm{~m}$ below the Culebra dolomite.

The work plan for site characterization of the Gnome-Coach site (DOE, 2002) separated efforts concentrated on potential contamination of the surface and shallow subsurface from efforts concentrated on the deep subsurface. Corrective action investigations were conducted for the surface and shallow subsurface in 2002 and 2003 and concluded that the site's surface could be closed with no further action (DOE, 2004). The two contaminant sources in the deep subsurface (Gnome cavity and the tracer test) are fundamentally different from each other in terms of both their stratigraphic location and release mechanisms, and are accordingly treated separately in the work plan. The only release scenario identified for the Gnome cavity is hypothetical and dependent on a system failure involving an assumed failed borehole seal, sufficient fluid to dissolve and transport contaminants, and the timing of sufficient pressure build-up prior to salt creep sealing the pathway (Earman et al., 1996). As a result, the strategy for the nuclear cavity concentrates on evaluating completion and stemming data for the subsurface workings and using that information to assess migration potential.

Although the tracer test represents a smaller contaminant mass compared to the nuclear test, it is recognized in the work plan as having greater migration potential because the radionuclides are in direct contact with groundwater in the Culebra aquifer. There are several preexisting models of the Culebra aquifer and the tracer test at Gnome, and extensive research regarding the Culebra at the nearby Waste Isolation Pilot Plant (WIPP) site. As a result, the work plan specifies that the first step of the tracer test investigation will be a Data Decision Analysis (DDA) to determine whether additional site characterization data are needed prior to evaluating existing subsurface intrusion restrictions and determining longterm monitoring. Upon completion of the DDA, additional data will be collected if warranted, contaminant transport predictions will be completed and compared to current subsurface intrusion restrictions in regard to protection of human health and the environment, and appropriate long-term monitoring will be prescribed.

This document reports on a value of information analysis (VOIA) conducted for the tracer test at Gnome. This VOIA includes the aspects of the DDA specified in the workplan, and additionally includes the monetary value of groundwater in the analysis. The purpose is to determine the potential migration of radionuclides associated with the tracer test and to determine if additional characterization is economically justifiable to further reduce the uncertainty in those predictions.

\section{HYDROGEOLOGIC SETTING}

The geology and hydrogeology of the Project Gnome site are described by Gard (1968), Cooper (1962a, b), and Cooper and Glanzman (1971). Additional work related to the nearby WIPP site is discussed in detail below. The Gnome site is located in the northern portion of the Delaware Basin and is approximately $40 \mathrm{~km}$ southeast of Carlsbad, New 
Mexico (Figure 1). The Delaware Basin contains up to 5,550 m of sedimentary rocks deposited in a Permian-age sea.

The Project Gnome detonation occurred within bedded halite of the Salado formation (Cooper and Glanzman, 1971) (Figure 2). Underlying the detonation point are $350 \mathrm{~m}$ of Salado evaporites and $490 \mathrm{~m}$ of Castile Formation evaporites, followed by basin-fill clastics and carbonates. Overlying the detonation point are $170 \mathrm{~m}$ of Salado evaporites, the Rustler Formation, Dewey Lake Redbeds, and Quaternary alluvial deposits. The 110-m-thick Rustler Formation is predominantly composed of gypsum and anhydrite and generally has very low permeability. However, three units within the Rustler have been identified as aquifers: the Magenta dolomite, the Culebra dolomite, and a layer of dissolution residue at the interface of the Rustler and Salado formations. The Culebra, a 9 to $12 \mathrm{~m}$ thick dolomite located $150 \mathrm{~m}$ below land surface, was identified by Gard (1968) as important to groundwater transport at Gnome because it is the only widespread, laterally continuous, aquifer at the site. Though water quality in the Culebra is generally poor due to high dissolved solids, it is the only source of water throughout much of the area and is used to supply local ranches.

The understanding of Culebra hydrogeology, and geologic features influencing aquifer properties, has been greatly advanced in the northern Delaware Basin as a result of intensive investigations conducted on behalf of the WIPP site, located approximately $9 \mathrm{~km}$ to the northeast of Gnome (Figure 1). Though drilling and testing has primarily been to the north and east of Gnome, the body of work not only provides an abundance of hydraulic data, but also a conceptual model of the groundwater flow and transport characteristics of the Culebra applicable throughout the area. DOE (2009) provides a centralized summary of much of this research, with references to over fifty topic-specific publications.

The general conceptual model of the Culebra groundwater system developed for WIPP describes flow basically from the north to the south. At the WIPP site, east of Nash Draw (the surface expression of a collapse feature formed primarily by dissolution of halite from the Salado Formation), the Culebra is confined and does not receive modern recharge from rainfall. Recharge is observed in some parts of Nash Draw itself, particularly in the southeast arm. Discharge is ultimately to the Pecos River, though groundwater moving through Nash Draw flows to the southwest to discharge areas in the Malaga Bend area of the Pecos River, while flow east of Nash Draw is directed due south, eventually to discharge farther downstream. A groundwater divide, related to the recharge in southeastern Nash Draw, separates these two regimes. The position of the Gnome site within this conceptual framework is uncertain due to the lack of hydraulic head data in the Gnome area.

The Culebra is notable for the extremely wide variation in observed transmissivity. This variation is generally assumed to be due strictly to post-depositional processes (Holt, 1997; Holt and Powers, 1988). Hart et al. (2008) relate the spatial distribution of Culebra transmissivity as a function of the following: Culebra overburden thickness, dissolution of halite from the underlying Salado Formation, and occurrence of halite in units above or below the Culebra. Three broad transmissivity zones are mapped, with high values in the Salado dissolution zone (generally areas closer to the Pecos River, including Nash Draw and the Gnome site), very low values to the east of WIPP where halite is present in the Salado and Rustler formations, and a transition zone between these endmembers (Figure 3). The Gnome site occurs within the high transmissivity region located southwest of WIPP. The high transmissivity is the result of fractures across a variety of scales in the Culebra dolomite, 
caused by stress relief from erosion of overburden and accommodation of underlying dissolution, and absence of gypsum fillings within these fractures. The permeability pattern is shown in Figure 4 with the locations of hydraulic tests in the region.

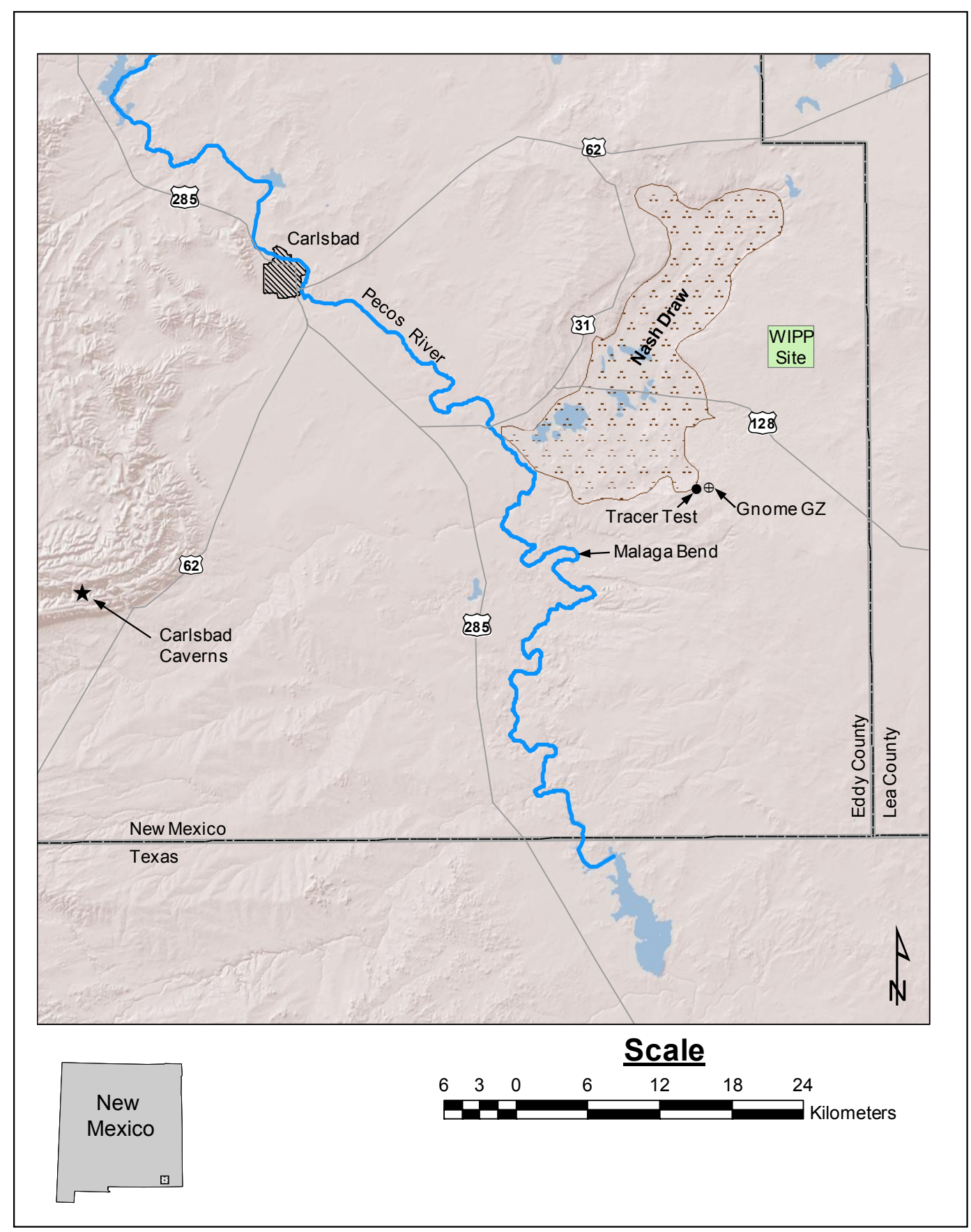

Figure 1. Project Gnome site located southeast of Carlsbad, including model domain boundary. 


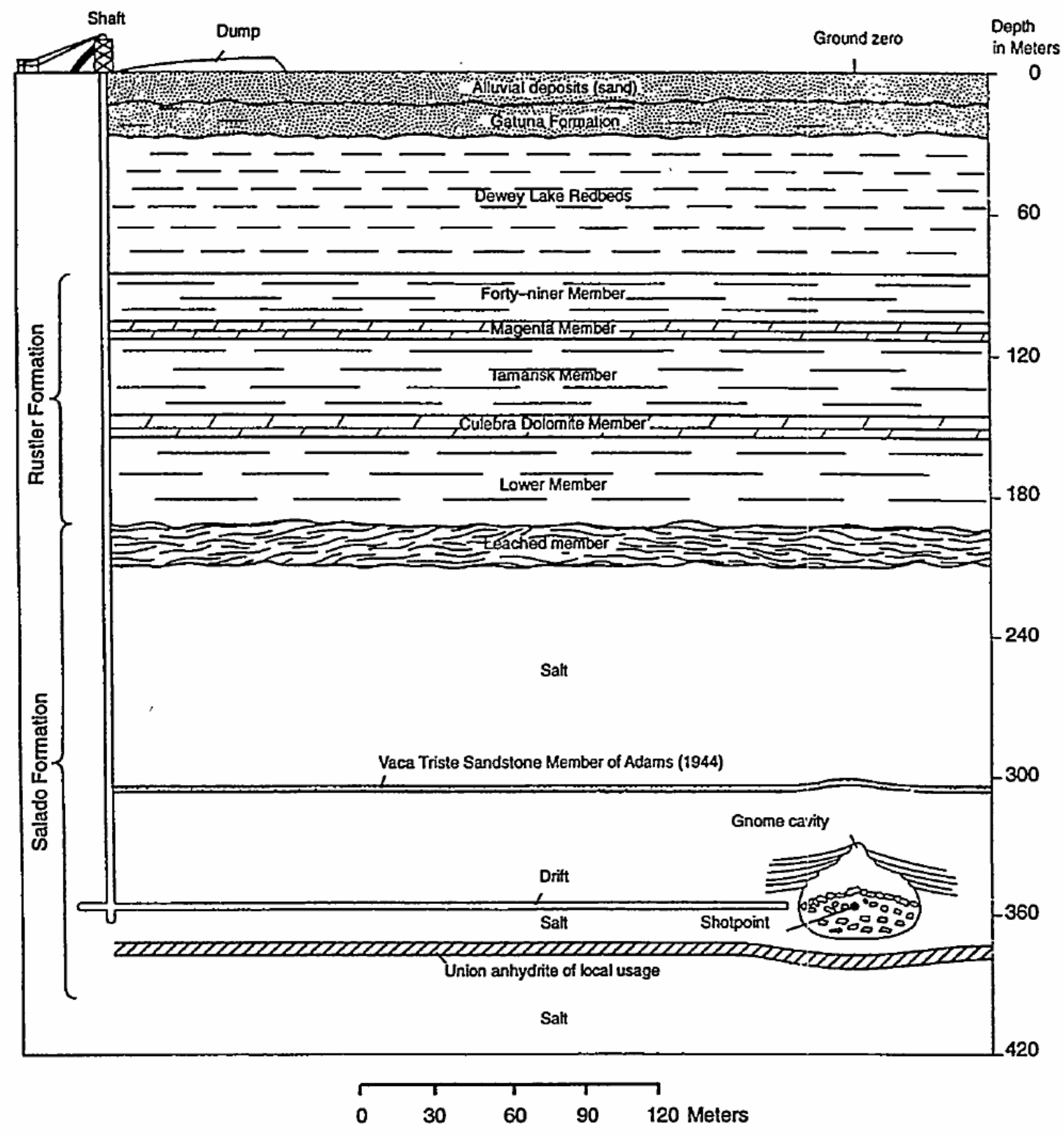

Figure 2. Cross section through the Project Gnome site showing the relation of nuclear cavity, drift, and shaft to local stratigraphy (modified from Gard, 1968). 


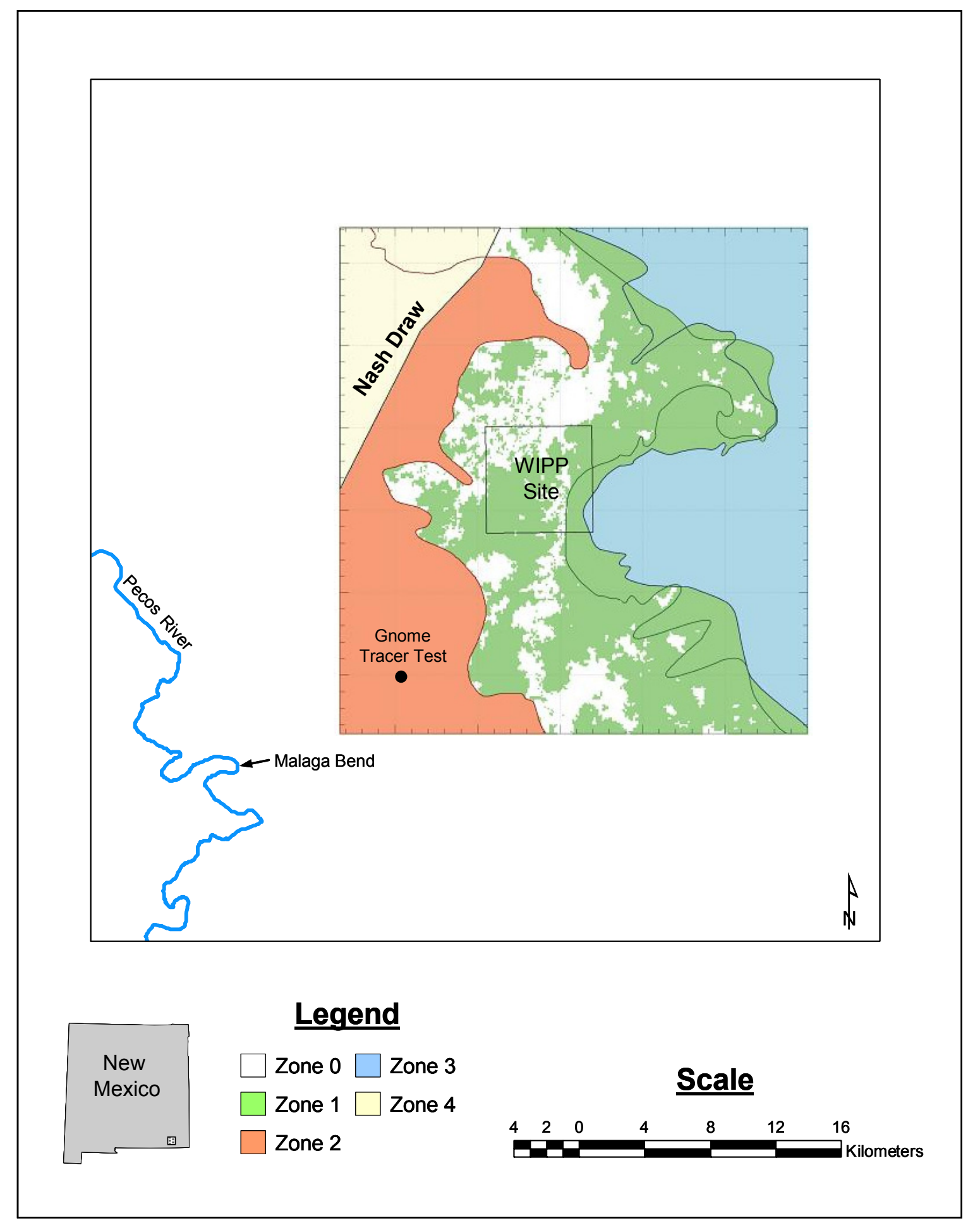

Figure 3. Example transmissivity zone map from Hart et al. (2009). The blue is the very low transmissivity zone where halite occurs above and below the Culebra. The orange high transmissivity zone coincides with where the underlying Salado halite is dissolved. The green and white areas are transitional between these endmembers. The tan region is outside the WIPP model domain. The WIPP site is shown by the square in the middle of the map and Gnome is indicated by the circle. 
Numerous tracer tests have been conducted within the Culebra dolomite to characterize flow and transport processes near the WIPP (e.g., Altman et al., 2002; Beauheim, 1987; Beauheim, 1989; Farnham, et al., 2000; Haggerty, 2000; Haggerty et al., 2000; Haggerty et al., 2001; Holt, 1997; Jones et al., 1992; Jones and Altman, 2000; Jones and Meigs, 2000; McKenna, 2000; McKenna et al., 2001; Meigs and Beauheim, 2001; Meigs et al., 2000; Moench, 1995; Ostensen, 1998). Two of the tracer tests (H-2 and H-4) suggest the prevalence of single-porosity or matrix-only transport. Three other tests (H-3, H-6, and H-11) show rapid breakthrough followed by a long slow tailing effect, which is indicative of a dual-porosity transport process. Fracture porosities were estimated to range between $5.0 \times 10^{-4}$ and $1.0 \times 10^{-3}$. Matrix porosities range between 0.1 and 0.25 for all tests.

\section{Gnome Tracer Test Description}

The Gnome tracer test was designed to estimate the dispersivity and effective porosity of the Culebra dolomite using the method presented by Grove and Beetem (1971). This information was desirable for improving the understanding and prediction of radionuclide transport in a fractured-rock aquifer similar to the carbonate aquifers present at the Nevada Test Site (Beetem and Angelo, 1964).

Grove and Beetem (1971) provide the theoretical development for analysis of a two-well recirculating tracer test. In this test, one well discharges from the aquifer and the second well injects at the same rate to create a steady-state flow field between the wells. It is important to note that this type of test results in a substantially different flow field than would exist under ambient conditions.

The design and operation of the tracer test are described by Beetem and Angelo (1964). Two wells were constructed: injection well USGS-8, approximately $915 \mathrm{~m}$ west of Project Gnome ground zero; and discharge well USGS-4, located $38 \mathrm{~m}$ due west of USGS-8. Deviation from the vertical in USGS-4 caused the wells to be separated by $55 \mathrm{~m}$ in the Culebra. Both wells are uncased through the 10.4-m thickness of the Culebra. A 15.24-cm-diameter steel pipe connecting the two wells at the surface provided for recirculation of the groundwater and tracers from the discharge well to the injection well. In the first phase of the test (February 9-15, 1963), the discharge well was pumped at $168 \mathrm{~L} / \mathrm{min}$ until the discharge and recharge pressure responses indicated that flow conditions between the wells were nearly in equilibrium. Unknown quantities of the conservative tracers, tritium and fluorescein, were then added to the injection line to determine their dilution factors for the subsequent tracer test. During this first phase, pumping continued for a total of seven days while samples were collected from the discharge line. The pump was shut off and fluid pressures were allowed to recover for two weeks prior to the initiation of the second phase of testing. Pumping for the second phase started on February 21, 1963, and steady-state conditions were reestablished, followed by the addition of tritium, ${ }^{137} \mathrm{Cs},{ }^{90} \mathrm{Sr}$, and ${ }^{131}$ I to the injection line. Records indicate that up to 50,10,10, and 4 Curies could be purchased for tritium, ${ }^{137} \mathrm{Cs},{ }^{90} \mathrm{Sr}$, and ${ }^{131} \mathrm{I}$, respectively, but the exact amounts added to the injection line are not clearly documented (Gardner and Sigalove, 1970). Grove and Beetem (1971) state that $18.5 \mathrm{Ci}$ of tritium were injected and unpublished notes from the USGS indicate that 1.5 Ci of ${ }^{137} \mathrm{Cs}, 1.0 \mathrm{Ci}$ of ${ }^{90} \mathrm{Sr}$, and $700 \mathrm{mCi}$ of ${ }^{131} \mathrm{I}$ were injected. Pumping continued for 16 days while samples were collected from the discharge line. The test was terminated on March 9, 1963, after the breakthrough curves were considered to be sufficiently developed for the analysis. The discharge/injection pipe system was dismantled, the pump in USGS-4 
was pulled, and the surface area was cleaned up (Beetem and Angelo, 1964); no available records describe efforts to remediate the Culebra dolomite and the radioactive tracers therein.

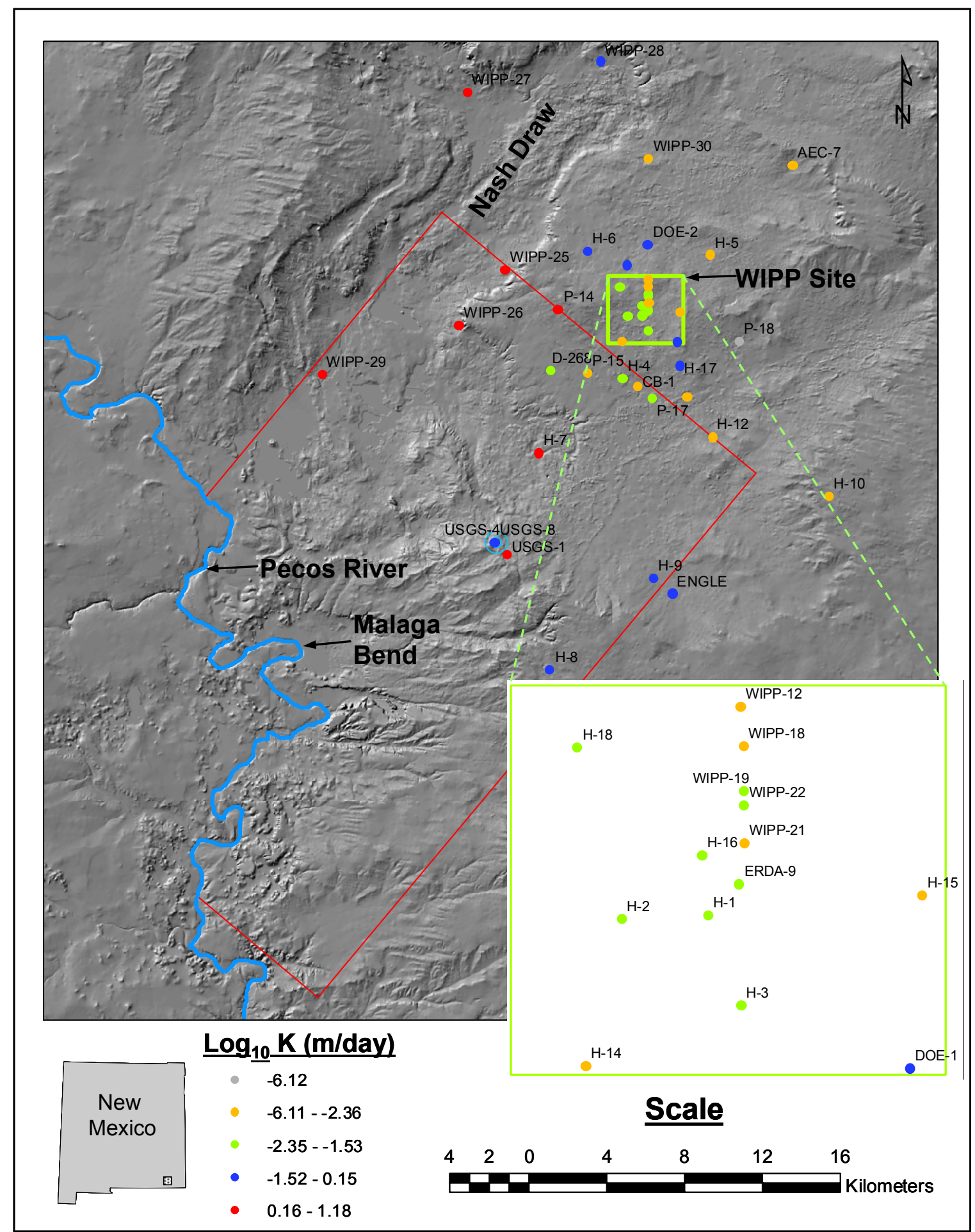

Figure 4. Measured hydraulic conductivity within the Culebra dolomite (data from Cauffman et al., 1990). 
Two breakthrough curves for tritium were obtained for the tracer test experiment (Figure 5). One breakthrough curve is available from Grove and Beetem (1971), with the tritium concentration expressed in relative units $\left(C / C_{0}\right)$. Translating these values into concentrations requires an assumption of the basis for the relative units. Typically, this is relative to the maximum concentration in the injection well. Assuming $18.5 \mathrm{Ci}$ of injected tritium and 7.76 days of injection at a rate of $241.9 \mathrm{~m}^{3} /$ day, the maximum concentration would be $9.85 \times 10^{6} \mathrm{pCi} / \mathrm{L}$ (at USGS-8). Therefore, this estimated maximum concentration at USGS-8 was used to convert the relative concentration data presented in Grove and Beetem into actual concentrations at USGS-4. The second available breakthrough curve was a handdrawn breakthrough curve from records obtained from the USGS (D. Wood, written communication, 1996). These data are presented in radioactive counts per minute, which are converted in Figure 5 to tritium concentrations ( $\mathrm{pCi} / \mathrm{L}$ ). The USGS data show consistently larger activities than the Grove and Beetem data. The difference is most likely due to an incorrect assumption for the $\mathrm{C}_{0}$ concentration associated with the Grove and Beetem data. The USGS data also show considerable scatter at early times, which may have been omitted by Grove and Beetem. Although there are slight differences in the data, the analysis of Pohll and Pohlmann (1996) suggests that the dispersivity and effective porosity required to simulate each dataset are almost identical. Since the Grove and Beetem data are from a peer-reviewed journal, these data are used for the tracer test analysis presented here.

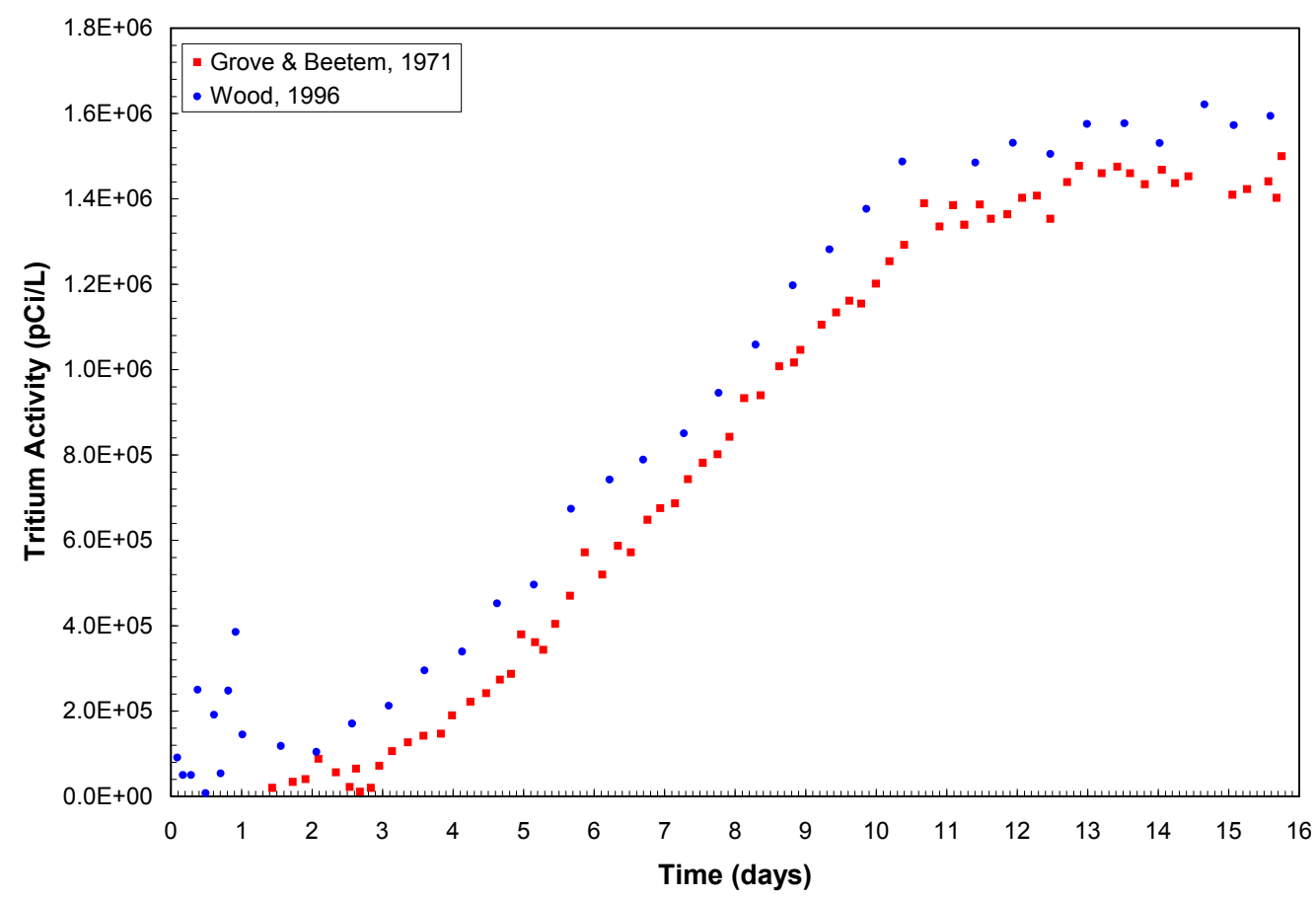

Figure 5. Measured tritium activity for the two-well tracer test from Grove and Beetem (1971) and Wood (USGS, written communication, 1996). 


\section{Tracer Test Analysis}

Although the Project Gnome tracer test has been evaluated previously (Grove and Beetem, 1971; Pohll and Pohlmann, 1996), this analysis reevaluates the test to determine the spatial distribution of tritium and ${ }^{90} \mathrm{Sr}$ after the test was terminated. The tracer test is analyzed using numerical models in a manner similar to Pohll and Pohlmann. MODFLOW-2005 (Harbaugh, 2005) and MT3DMS (Zheng and Wang, 1999) are used to simulate the migration of the two radionuclides both during and after the tracer test. Since measurements of tritium and ${ }^{90} \mathrm{Sr}$ are available at USGS-4 and USGS-8 following the tracer test (Conrad et al., 1998), the models simulate the period from February 21, 1963 to December 28, 2006. Measurements of ${ }^{137} \mathrm{Cs}$ were also taken, but all samples were less than the maximum contaminant level (EPA, 2000) of $200 \mathrm{pCi} / \mathrm{L}$, so further analysis was not performed.

A two-dimensional, fully confined model was created, centered on USGS-8 and $500 \mathrm{~m}$ on each edge. USGS-4 was located $55 \mathrm{~m}$ to the west of USGS-8. The model was discretized into 10,000 finite-difference grid cells, with each cell being $5 \mathrm{~m}$ square (Figure 6). The model thickness was set to $10.4 \mathrm{~m}$ to represent the average thickness of the Culebra dolomite in the vicinity of the tracer test. The east and west boundaries were specified head boundaries to represent a regional head gradient $\left(4.2 \times 10^{-4}\right)$ in the vicinity of the Gnome Site. Although the head gradient is somewhat uncertain in the vicinity of the tracer test, this value was chosen to be consistent with the value used by Pohll and Pohlmann (1996) and represents the gradient calculated by using USGS-4 and H-7 (H-7 is located approximately $5 \mathrm{~km}$ to the northeast of Gnome). The north and south boundaries were simulated as no-flow.

The simulation was subdivided into three steady-state stress periods. The first two stress periods represent the nearly 17 days over which the tracer test was performed. During these stress periods, USGS-8 was injecting at a rate of $242 \mathrm{~m}^{3} /$ day, and USGS-4 was pumping at the same rate. Two stress periods were used so that the tracer injection period ( 7.75 days) could be differentiated within the solute transport model from the following period in which no tracer was added to the system.

The flow model was calibrated by adjusting the hydraulic conductivity until there was a reasonable agreement between the simulated and observed $(11 \mathrm{~m})$ drawdown at USGS-4. A hydraulic conductivity of $2.5 \mathrm{~m}$ /day was found to yield an acceptable agreement between the simulated and observed drawdown. This hydraulic conductivity is slightly larger than that determined by Pohll and Pohlmann (1996). The difference is most likely related to minor differences in the size of the model domain and boundary conditions used. This hydraulic conductivity measurement is in the upper quartile of all measurements located within the region of halite dissolution from WIPP-related research. A hydraulic conductivity of $2.5 \mathrm{~m}$ /day is equivalent to a transmissivity of $23 \mathrm{~m}^{2} /$ day (aquifer thickness is $10.4 \mathrm{~m}$ ). Cooper and Glanzman (1971) reported a transmissivity of $43 \mathrm{~m}^{2} /$ day for USGS-1, which is located approximately $900 \mathrm{~m}$ southeast of USGS-4. 


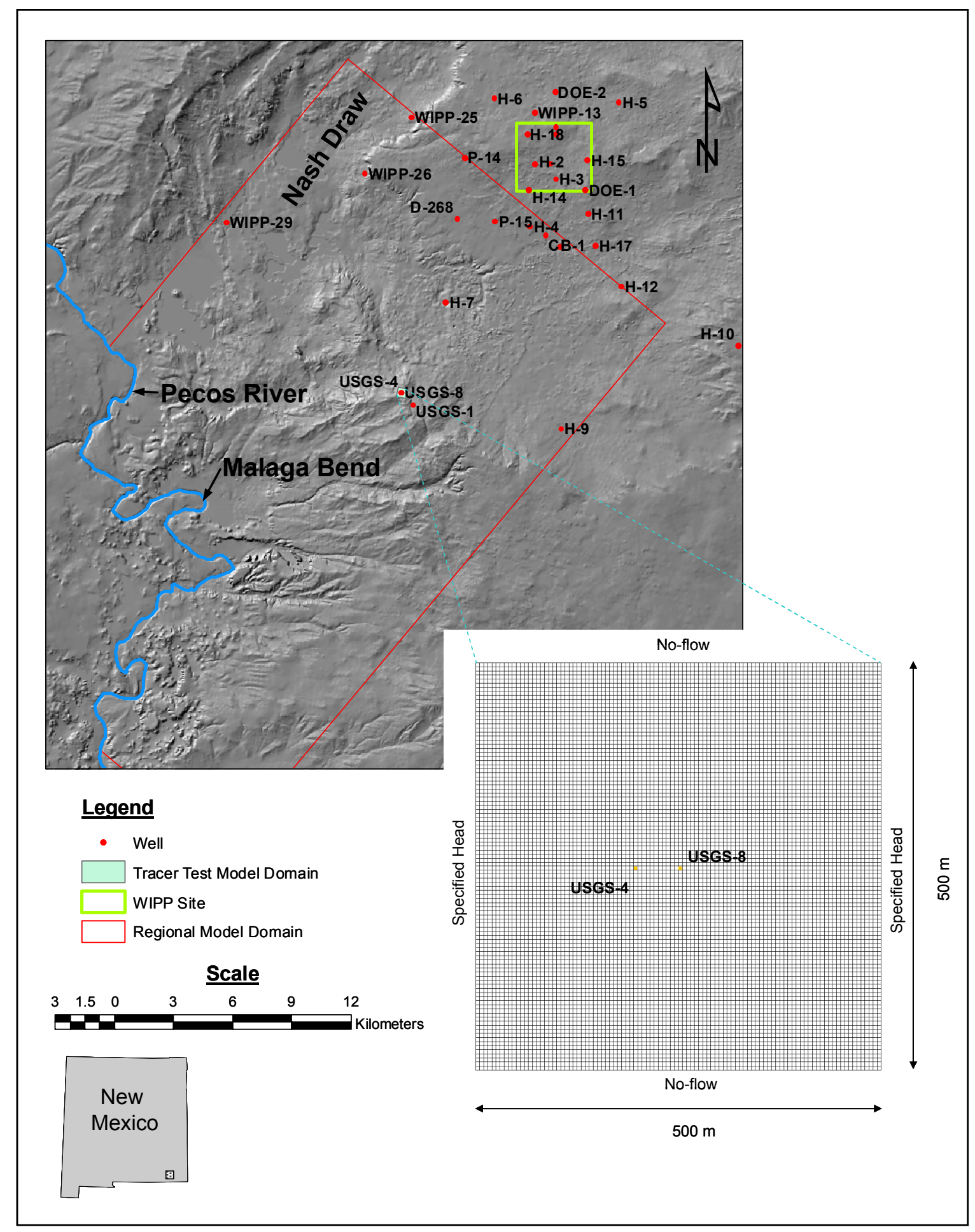

Figure 6. Groundwater model domain used in the tracer test analysis. 
The solute transport model had to be modified to account for the recirculation of the tracers. A simple mass-balance algorithm was used to calculate the concentration of the injection fluid as

$$
C_{i n j}=\left(\frac{Q_{i n j} C_{p u m p}+Q_{t r} C_{t r}}{Q_{t o t}}\right)
$$

where $C_{i n j}$ is the actual concentration of the tracer that is injected into the aquifer, $C_{\text {pump }}$ is the concentration at the pumping well (USGS-4) calculated by MT3DMS, $C_{t r}$ is the concentration of the tracer injection fluid prior to mixing with the recirculated fluid, $Q_{i n j}$ is the volumetric flow rate at the injection line $\left(242 \mathrm{~m}^{3} /\right.$ day $), Q_{t r}$ is the volumetric flow rate of the tracer flow line $\left(0.027 \mathrm{~m}^{3} /\right.$ day $)$, and $Q_{t o t}$ is the sum of $Q_{i n j}$ and $Q_{t r}$. It is important to note that the tracer was injected only for the first 7.75 days; $Q_{t r}$ and $C_{t r}$ were set to zero thereafter.

The solute transport model was calibrated by simulating tritium transport while adjusting the effective porosity and dispersivity until there was a reasonable agreement between the simulated and observed breakthrough concentrations as USGS-4 and USGS-8. Unlike the calibration of Pohll and Pohlmann (1996), both tracer test and post-tracer test tritium concentration data were used in the calibration. The results of the tritium calibration simulation are shown in Figures 7 and 8 for USGS-4 and USGS-8, respectively. The calibrated parameters were 0.115 and $26.0 \mathrm{~m}$ for effective porosity and dispersivity, respectively. The model slightly underpredicts the tritium concentration at USGS-4 during the tracer test, while overpredicting after the tracer test. The model is in excellent agreement at USGS-8 (the injection well) following the tracer test. The calibrated value for effective porosity is in agreement with the range of matrix porosities $(0.1$ to 0.25$)$ calculated for the tracer tests at the nearby WIPP site (Jones et al., 1992; Meigs et al., 2000). The longitudinal dispersivity is larger than the range $(0.8$ to $2.0 \mathrm{~m})$ reported by Jones et al. (1992). The larger longitudinal dispersivity value found at the Gnome site may be due to increased fracturing within the high transmissivity zone (zone 2) identified by Hart et al. (2009) and the fact that tracer tests at the WIPP Site were not performed within this high transmissivity zone.

Numerous investigators have identified matrix diffusion as a potentially important process for contaminant transport within the Culebra dolomite at the WIPP Site (e.g., Jones et al., 1992; Holt, 1997; Ostensen, 1998; Haggerty et al., 2000; Haggerty et al., 2001; Altman et al., 2002). Given the fractured nature of the Culebra dolomite, and the potential for solute diffusion into matrix blocks, additional calibration simulations were performed to determine if matrix diffusion is an important process at the Gnome Site. The matrix diffusion simulations employed a single-rate diffusion model using MT3DMS. An automated calibration procedure was used in which fracture and matrix porosity, longitudinal dispersivity, and the matrix diffusion rate coefficient were allowed to vary. The results indicate that matrix diffusion is not an important process, as evidenced by a poorer fit between the simulated and measured breakthrough curves. At the WIPP site, matrix diffusion was found to be important where hydraulic conductivities are larger than $\sim 6 \times 10^{-2} \mathrm{~m} /$ day; tracer tests were not performed within the high transmissivity zone (zone 2 in Figure 3). The hydraulic conductivity measured at the Gnome tracer test (average of USGS-1, USGS-4, and USGS-8) is $3 \mathrm{~m} /$ day, while the largest hydraulic conductivity measured at a WIPP tracer test was nearly an order-of-magnitude lower $(0.4 \mathrm{~m} /$ day $)$. The larger permeabilities observed at the Gnome Site may be indicative of increased fracturing 
and smaller matrix block size, which would result in rapid mass transfer between the fracture and matrix. Under these conditions, matrix diffusion does not govern solute transport.
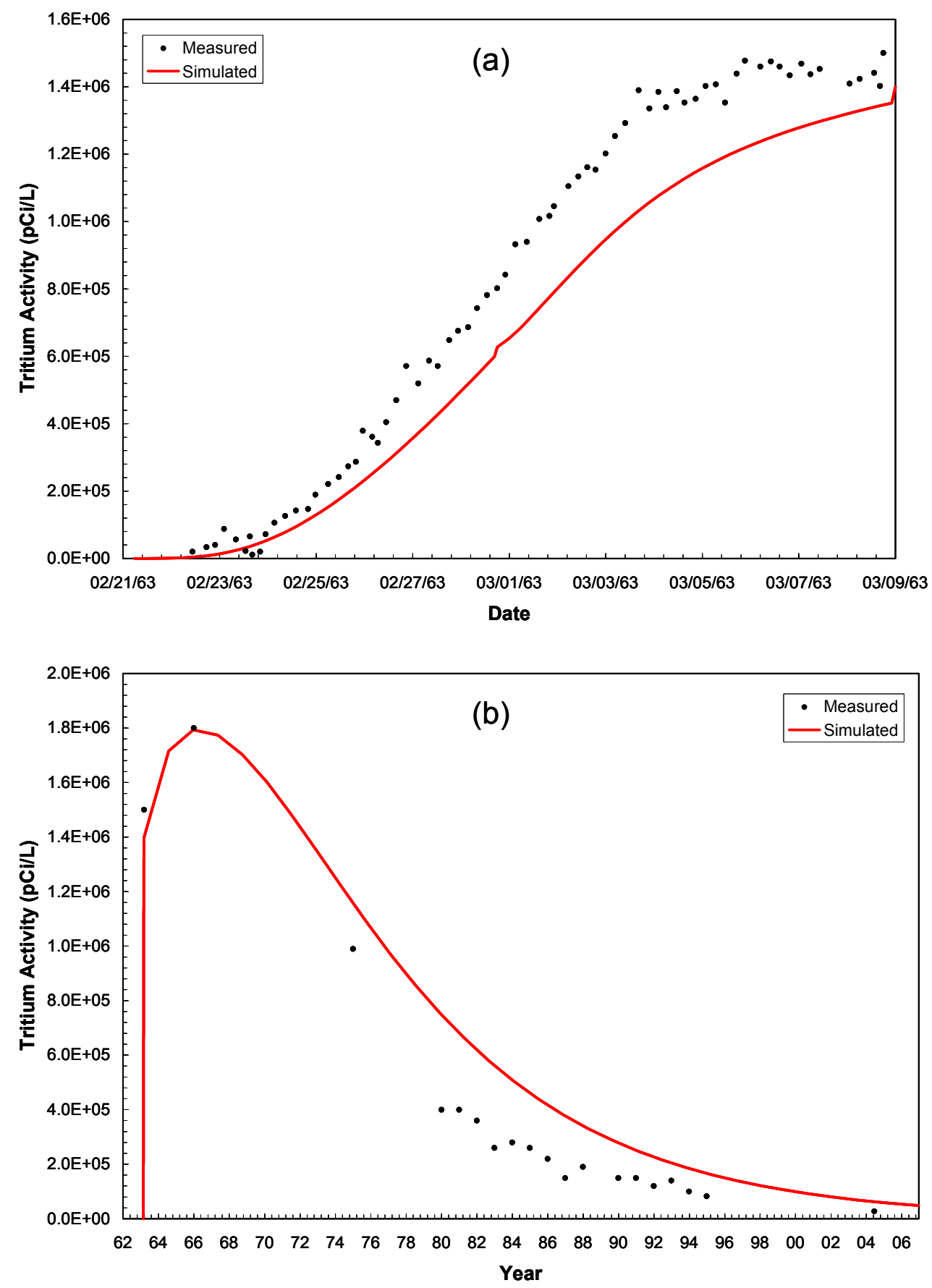

Figure 7. Simulated and measured tritium concentrations at USGS-4 (a) during the tracer test, and (b) following the tracer test. 


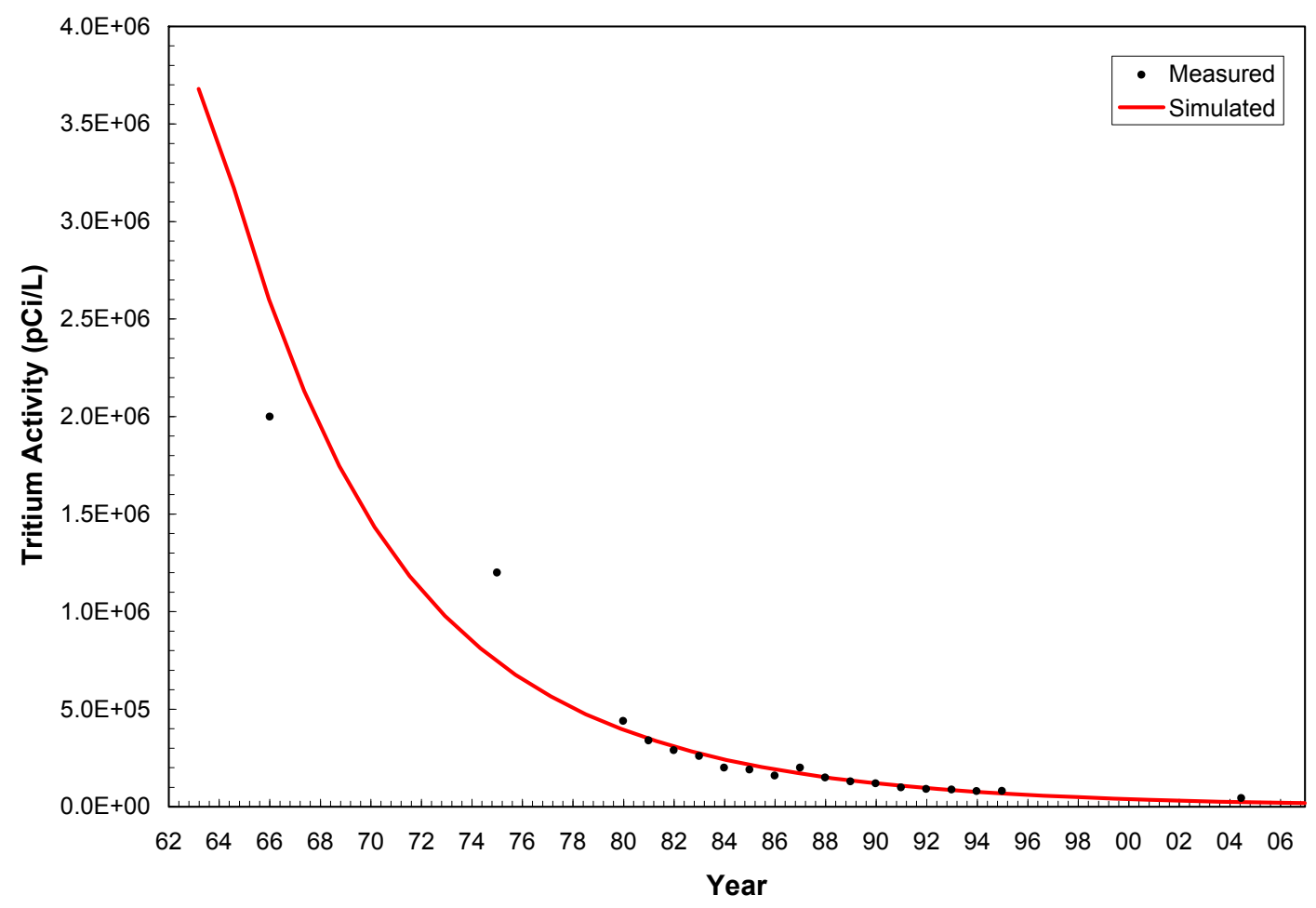

Figure 8. Simulated and measured tritium concentrations at USGS-8 following the tracer test.

Following the tritium calibration, ${ }^{90} \mathrm{Sr}$ was simulated using the retardation factor (i.e., sorption) as a calibration factor. This calibration procedure was terminated prior to completion due to large differences between the simulated and observed ${ }^{90} \mathrm{Sr}$ concentrations. This called into question the mass injected during the tracer test. Although Beetem and Angelo (1964) indicate that $10 \mathrm{Ci}$ of ${ }^{90} \mathrm{Sr}$ may have been purchased for the test, it is documented that for tritium, much less was used than approved for purchase. Unpublished USGS field books suggest that $1.0 \mathrm{Ci}$ of ${ }^{90} \mathrm{Sr}$ may have been injected. A $10 \mathrm{Ci}$ injection of ${ }^{90} \mathrm{Sr}$ resulted in simulated concentrations nearly two orders of magnitude larger than measured, while a $1.0 \mathrm{Ci}$ injection led to concentrations one order of magnitude too high. Therefore, the amount of ${ }^{90} \mathrm{Sr}$ injected was adjusted to reach agreement between simulated and measured concentrations (Figure 9). Excellent agreement was reached with an injected concentration of $0.18 \mathrm{Ci}$, and did not require consideration of sorption.

Given that the best-fit ${ }^{90} \mathrm{Sr}$ injection mass is not only lower than the allowed purchase amount, but also lower than the informal field notes indicate, calibration was attempted using the injection mass from the field notes $(1.0 \mathrm{Ci})$ and including sorption. A total of three simulations were evaluated, each assuming that the $1.0 \mathrm{Ci}$ of ${ }^{90} \mathrm{Sr}$ was injected during the tracer test. Lynch and Dosch (1980) reported distribution coefficients for ${ }^{90} \mathrm{Sr}$ that generally range between 0.5 to $5.0 \mathrm{~mL} / \mathrm{g}$, although one value was reported as high as $31 \mathrm{~mL} / \mathrm{g}$. Assuming that the bulk density for dolomite ranges between 1.5 and $2.8 \mathrm{~g} / \mathrm{cm}^{3}$ (Reeves et al., 1987 ) for fractured rock and matrix, respectively, and the effective porosity is 0.115 , bulk retardation coefficients would range between 7.5 and 123. One additional simulation was done assuming no retardation. 

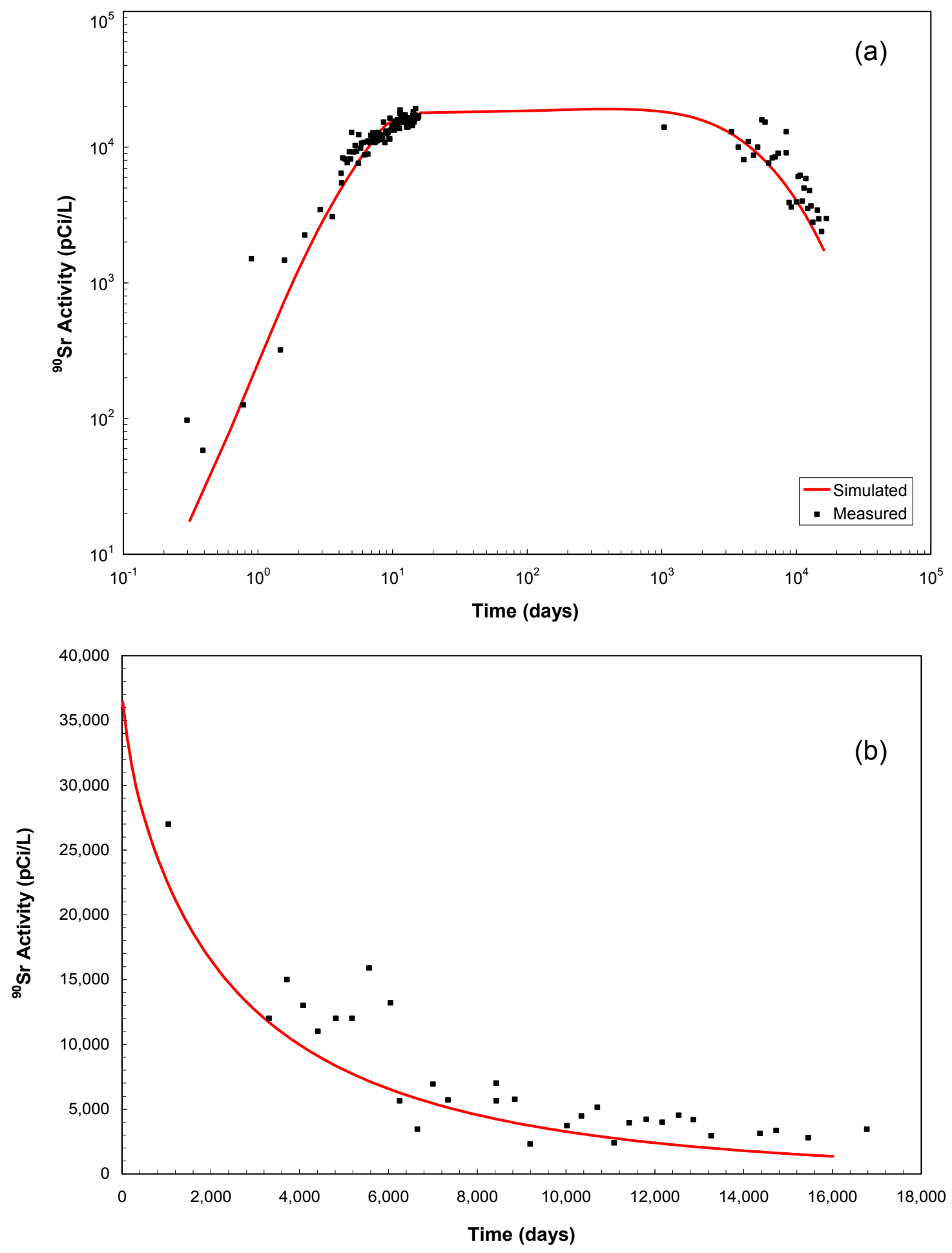

Figure 9. Simulated and measured 90Sr concentrations at (a) USGS-4 and (b) USGS-8. 
The results of this analysis are shown in Figure 10. Using a source mass of $1.0 \mathrm{Ci}$ resulted in simulated concentrations at the injection well (USGS-8) that are far in excess of measured values. The simulation that assumed no sorption $(\mathrm{R}=1.0)$ and $1.0 \mathrm{Ci}$ of ${ }^{90} \mathrm{Sr}$ yielded concentrations approximately one order of magnitude too large at the pumping well (USGS-4). Increasing the retardation to 7.5 yielded concentrations that are more consistent with the measured values at USGS-4, but the decreased concentrations over time are not simulated properly. Increasing the retardation to 123 yielded simulated concentrations at USGS-4 that are well below measured values.

The calibration effort indicates that the measured data cannot be replicated under the assumption that $1.0 \mathrm{Ci}$ of ${ }^{90} \mathrm{Sr}$ was injected during the tracer test even when reversible sorption is included in the model conceptualization. Although authorized to purchase $10 \mathrm{Ci}$, and field notes indicating an injection of $1.0 \mathrm{Ci}$, the breakthrough data suggest an injection mass of approximately $0.18 \mathrm{Ci}$ for ${ }^{90} \mathrm{Sr}$.

\section{REGIONAL GROUNDWATER MODEL}

A regional groundwater flow and transport model was constructed to determine the potential for long-term migration of radionuclides from the tracer test. The model is a tool for assessing the value of collecting additional information at the site, not a definitive predictor of transport behavior. As such, there are some differences between the Gnome model presented here and models developed for the WIPP site. These differences are primarily due to simplifications enacted to ease the Gnome analysis, and also to the relative sparseness of data in the Gnome and downgradient area, relative to the considerable information closer to WIPP. Points of discrepancy are noted below, and in no case should be construed as commentary on the WIPP-related research.

\section{Flow Model}

MODFLOW-2005 (Harbaugh, 2005) is used to simulate the hydraulic head distribution and groundwater flux in the Culebra dolomite, given certain aquifer parameters including hydraulic conductivity and regionally prescribed head boundary conditions. A steady-state model is assumed. Transient conditions are observed in some portions of the Culebra aquifer and are ascribed to recharge and leakage associated with Nash Draw, potash mine discharge in Nash Draw, and to leakage through unplugged boreholes (DOE, 2009). This can complicate using head values collected at different times. Head data used to define the boundary conditions for the model were obtained from Cauffman et al. (1990). Although these data are referred to as undisturbed by Cauffman et al. (1990), more recent data indicate that hydraulic heads have increased by 1 to $3 \mathrm{~m}$ from 2003 to 2007 (DOE, 2009). The head data obtained from Cauffman et al. (1990) generally represent measurements taken between 1977 and 1981 when the pressures were relatively stable, but a few measurements were taken as late as 1988 when earlier data were not available. A potentiometric map was constructed using the data obtained from Cauffman et al. (1990) and more recent data (2004) obtained from the WIPP Site database. A comparison of the two potentiometric maps shows localized differences, but the general pattern remained the same. More importantly, the head values along the model boundaries are nearly identical. 

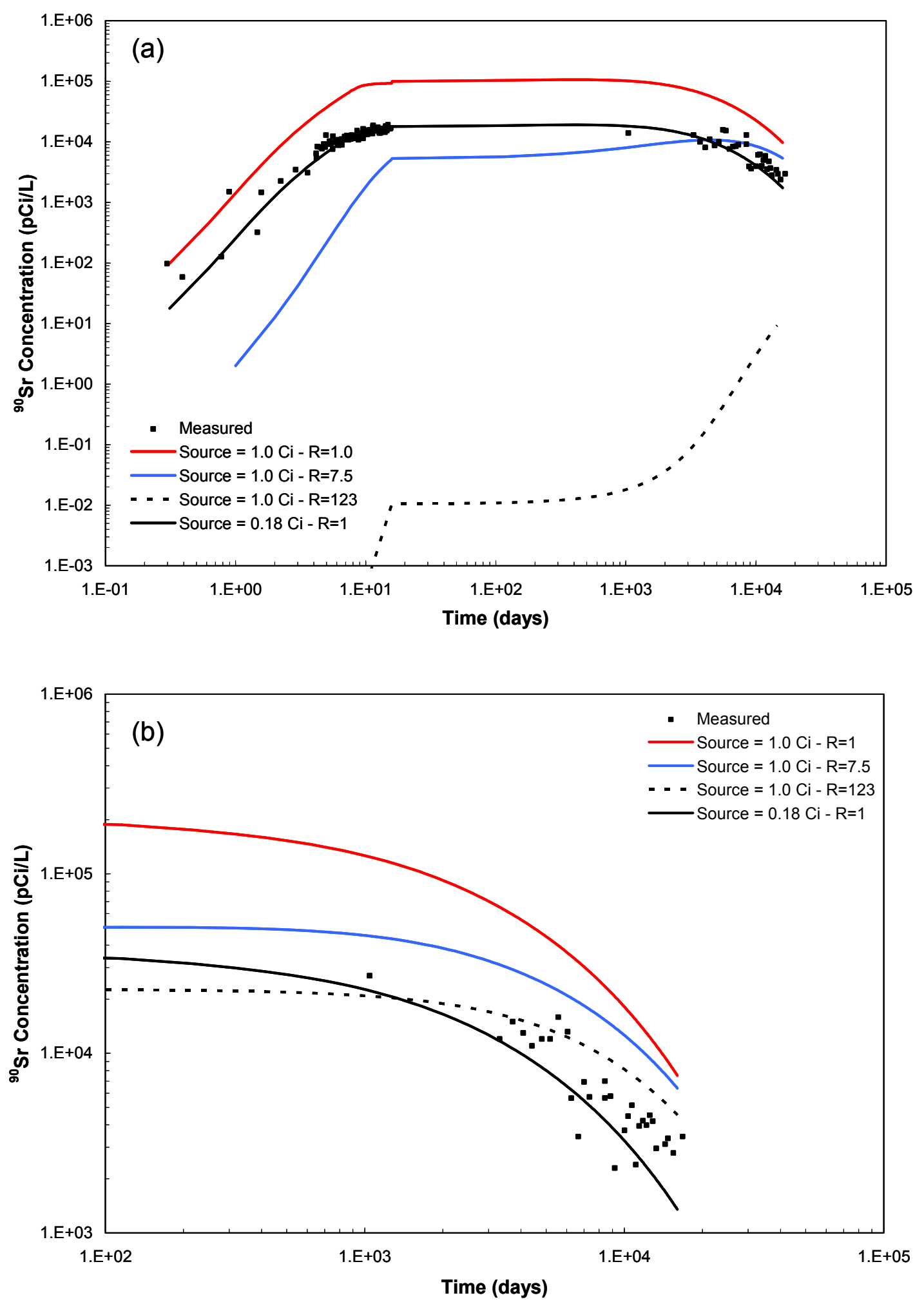

Figure 10. Simulated and measured ${ }^{90} \mathrm{Sr}$ concentrations at USGS-4 (a), and USGS-8 (b) for various source injection masses and retardation values. 
The model domain was selected to take advantage of the hydraulic head data adjacent to the WIPP site and an assumed discharge point of the Culebra aquifer at the Pecos River. The domain was structured such that radionuclides introduced during the Gnome tracer test would migrate toward the boundary associated with the Pecos River (Figure 11). This southwest-directed flow is in contrast to the predominantly southerly flow depicted for the Culebra in WIPP models (Hart et al., 2009), and results largely from neglecting the groundwater divide depicted in the WIPP models as a consequence of recharge in southeastern Nash Draw. An additional factor is a less sophisticated transmissivity distribution in the Gnome model that does not reproduce a structurally controlled north-south high-transmissivity zone observed in the southeastern portion of the WIPP site. These differences are considered tolerable for the Gnome analysis for several reasons. First, the location of the Gnome site with respect to the groundwater divide is unknown. Given the proximity of Gnome to Nash Draw, it is possible Gnome is west of the recharge-sustained divide, and that assumption is more conservative in that the flow path to the Pecos River is shorter. Second, Gnome and the downgradient region are entirely contained within the high transmissivity zone associated with dissolution of Salado halite. As such, the complexities associated with the lower transmissivity transitional zones in the Culebra are not critical to the Gnome flow problem. Finally, the metric of concern in the Gnome decision-support model is volume of affected groundwater, irrespective of direction of flow.

The entire perimeter of the model is simulated with specified head boundary conditions. The magnitude of the hydraulic heads was determined by interpolating both measured hydraulic head data and surface elevations associated with the Pecos River. The surface elevations for the Pecos River were extracted from a 30-m Digital Elevation Model (DEM). A kriging algorithm was used to interpolate the head values to the domain boundary. Locations of the hydraulic head measurement points and interpolated potentiometric map are shown in Figure 11.

The two-dimensional model grid consists of 73,500 (210 x 350) finite-difference cells each being $100 \mathrm{~m}$ square on edge and $10.4 \mathrm{~m}$ in thickness. Because the area to the west of the Pecos River is not simulated, these cells are not active in the model, which results in an active model area of 59,700 hectares. The model grid is rotated 40 degrees east of north about the southwest corner of the model (580773, 356026440 UTM-NAD27-Zone 13). All model cells are simulated as confined.

A total of 22 hydraulic conductivity measurements were used to describe the spatial hydraulic conductivity distribution within the model domain. Although more measurements were available around the WIPP site, many of these measurements are located east of the region of halite dissolution and have significantly lower magnitudes. Therefore, the 22 values used to construct the hydraulic conductivity field are indicative of the Culebra dolomite as suggested by Lappin (1988). Also included in this dataset is the hydraulic conductivity interpreted from the tracer test experiment. 


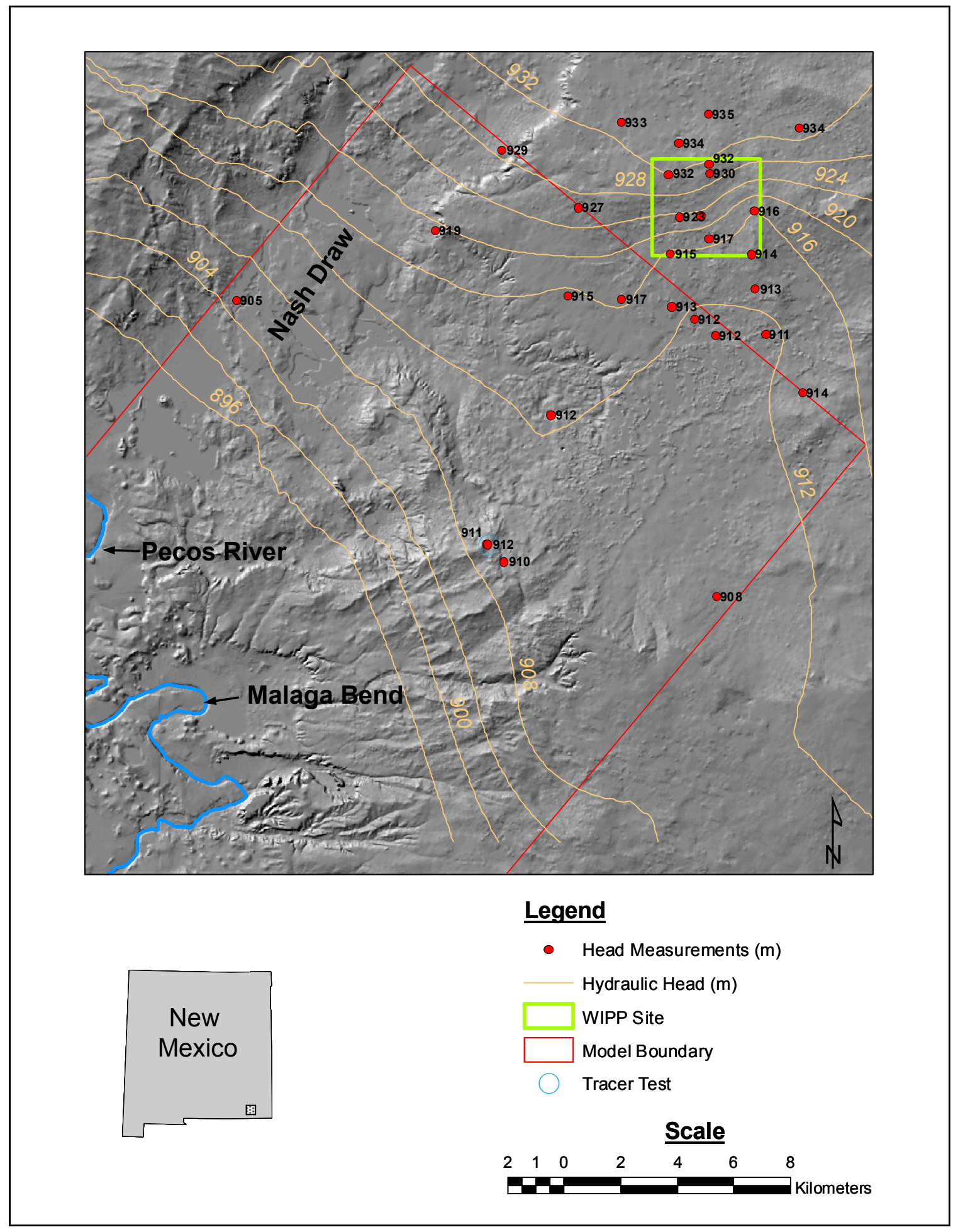

Figure 11. Location of head measurements used to define the specified head boundary with selected values of head measurements.

A geostatistical analysis was performed to assess the spatial correlation of the $\log _{10}$ transformed hydraulic conductivity values. A spherical semi-variogram was fit to the 
experimental semi-variogram, which resulted in a correlation scale of $6 \mathrm{~km}$, consistent with the analysis of Pohlmann and Andricevic (1994). The mean and variance of the log 10 transformed (from $\mathrm{m} /$ day units) hydraulic conductivity measurements are -0.29 and 1.00 , respectively. The variance or sill value used in this analysis is lower than that used by Hart et al., 2009 which is consistent with the fact that their analysis covered a larger region and therefore more heterogeneity. Hart et al., 2009 utilized a slightly larger range parameter for their simulated variogram $(9,500 \mathrm{~m})$, again likely because the modeled region is larger.

The hydraulic conductivity field is represented as a second-order stationary Gaussian random field using $\log _{10}$ transformed hydraulic conductivity. Random fields are conditioned on the measurements, while unsampled locations are simulated using a sequential Gaussian simulation (SGS) algorithm (Deutsch and Journel, 1992). A single realization of hydraulic conductivity is shown in Figure 12, which uses the 22 existing hydraulic conductivity measurements.

\section{Transport Model}

Radionuclide transport was simulated with RWHet (LaBolle, 2003). RWHet is a random walk particle tracking model designed to simulate advection and dispersion in heterogeneous permeable media. The transport model is used to predict radionuclide transport as derived by the tracer test.

Although four radionuclides (tritium, ${ }^{137} \mathrm{Cs},{ }^{90} \mathrm{Sr}$, and ${ }^{131} \mathrm{I}$ ) were used in the tracer test, only two (tritium, ${ }^{90} \mathrm{Sr}$ ) led to concentrations above the maximum contaminant level (MCL) following the test. Of these two radionuclides, ${ }^{90} \mathrm{Sr}$ was found to migrate further at levels above the MCL $(8 \mathrm{pCi} / \mathrm{L})$. This is a result of the complex interplay between the source mass, radioactive decay rate, and magnitude of the MCL for each radionuclide. For example, the source mass of tritium is over two orders of magnitude larger than ${ }^{90} \mathrm{Sr}$, but the half-life of tritium is approximately half that of ${ }^{90} \mathrm{Sr}$. Likewise, the MCL for ${ }^{90} \mathrm{Sr}$ is three orders of magnitude less than that for tritium. It is important to note that in other systems, tritium may migrate further at levels above the MCL due to increased retardation of ${ }^{90} \mathrm{Sr}$. Only ${ }^{90} \mathrm{Sr}$ transport is considered in this analysis because it has the potential to contaminant a larger volume of the Culebra aquifer. The transport parameters were all derived from the analysis of the two-well tracer test described above. All of the transport parameters were assumed to be deterministic and are listed in Table 1. 


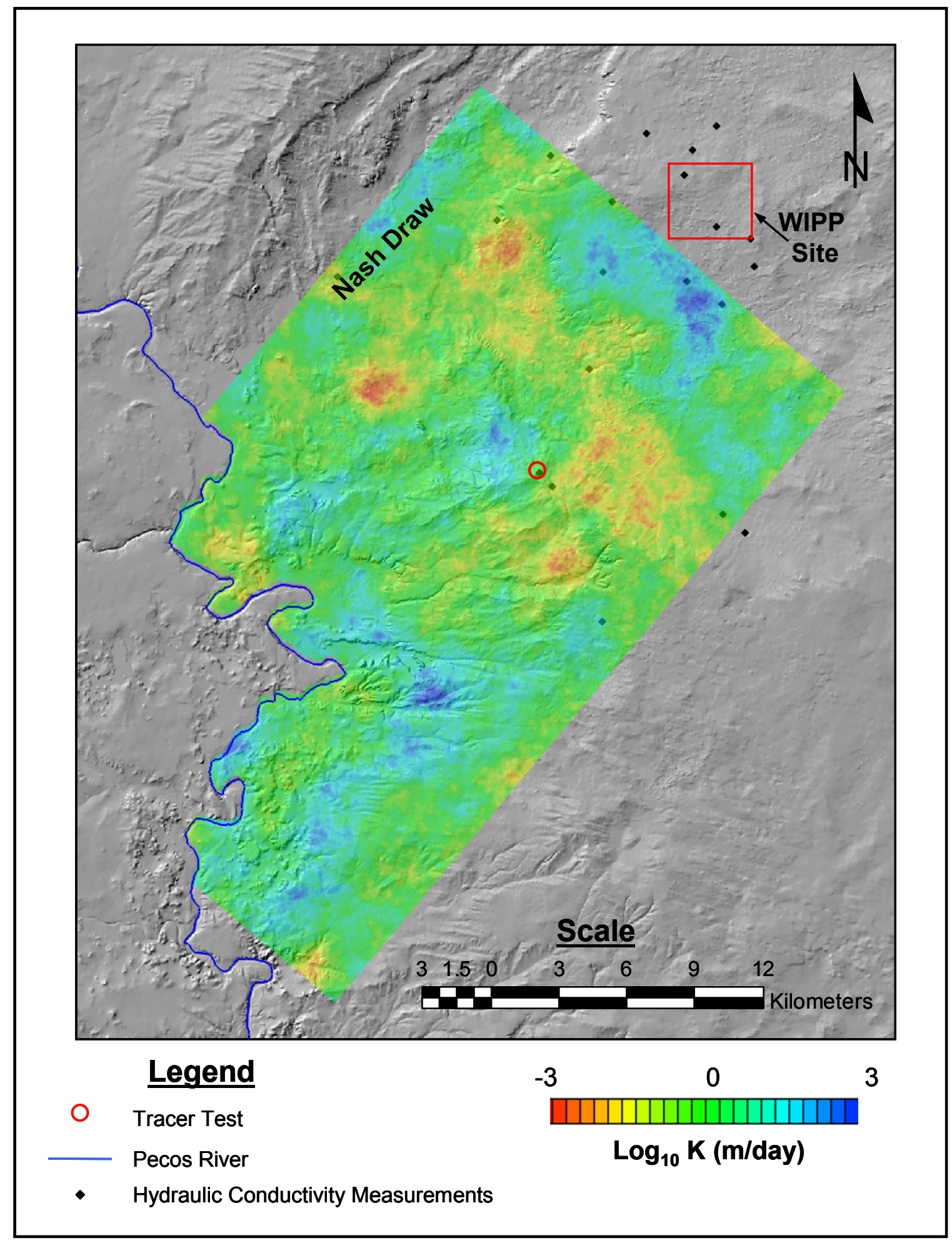

Figure 12. Single realization simulation of the hydraulic conductivity field. 
Table 1. Solute transport parameters used in the regional model.

\begin{tabular}{lc}
\hline Parameter & Value \\
\hline Effective Porosity & 0.11 \\
Longitudinal Dispersivity & $26 \mathrm{~m}$ \\
Transverse Dispersivity & $2.6 \mathrm{~m}$ \\
Retardation & 1 \\
\hline
\end{tabular}

Given that the simulated ${ }^{90} \mathrm{Sr}$ plume following the tracer test was approximately circular with a diameter of $100 \mathrm{~m}$, the entire ${ }^{90} \mathrm{Sr}$ mass was placed in a single grid cell coincident with the centroid of the plume on March 17, 1963. This places the center of the initial plume location at an easting of $605857 \mathrm{~m}$ and northing of $3570079 \mathrm{~m}$ (UTM-NAD27-Zone 13) at the finite difference cell 130, 114 (column, row in MODFLOW indices).

The transport model simulates ${ }^{90} \mathrm{Sr}$ for a period of 1,000 years following the termination of the tracer test. Therefore, the model terminates on March 17, 2963. The model calculates ${ }^{90} \mathrm{Sr}$ concentrations throughout the simulation period at every cell in the model domain. This output was synthesized by calculating the maximum concentration for every model cell and then converting the maximum simulated concentrations into a binary variable (i) that represents whether or not the concentration exceeded the MCL of $8 \mathrm{pCi} / \mathrm{L}$ during the simulation period. This information can be plotted to delineate the spatial probability of the contaminant plume.

\section{VALUE OF INFORMATION ANALYSIS}

\section{General Approach}

A value of information analysis (VOIA) evaluates the benefit of collecting additional information to reduce uncertainty in a specific decision making context (Yokota and Thompson, 2004). The decisions that need to be made for Gnome include:

- Should additional characterization data be collected prior to evaluating subsurface restrictions and determining long-term monitoring?

- If additional data are needed, where should these measurements be taken?

- If additional data are needed, how many measurements should be taken?

There are two schools of thought on the application of a VOIA. For certain applications, it may be difficult to quantify the economic benefit or cost for a certain decision. For example, economists routinely calculate a societal value for averting premature morbidity and mortality, but there are no widely accepted values for this purpose. In cases where monetary values are difficult to ascertain, the analyst will typically quantify the worth of a measurement by its affect on prediction uncertainty, but will not specifically quantify the economic loss of improper decisions. Although this method is helpful in determining the value of information, it adds a level of subjectiveness to the decision-making process. Specifically, this type of analysis can discriminate between multiple data collection activities, but cannot determine when enough data have been collected. An alternative approach is to cast the problems in terms of a quantifiable economic benefit or cost. This approach creates a direct link between the cost of the data collection activity and the cost associated with 
making a decision. In this case, the decision to stop collecting data is simple because one stops when the cost of additional information exceeds the worth of the data.

VOIAs are based on Bayesian theory which combines uncertainties in the system behavior (e.g., location and movement of the radionuclide plume) and the economic costs of the project. Bayes Theorem is used in a variety of scientific disciplines, but its use in decision theory has grown rapidly since the 1960s. More specifically, Bayesian analysis can be used to quantify the value of collecting additional information to reduce uncertainty. The phrase value of information analysis has been coined for this type of analysis. In a mathematical sense, a VOIA is just another application of Bayes Theorem that combines system uncertainty with an economic analysis. System uncertainty is typically derived from a mathematical model that can make predictions of the system, in this case a groundwater flow and transport model. Prior uncertainty is based on either a subjective interpretation of the input parameters required by the model or actual field data collected to date. The mathematical model is used to transfer the uncertainty in the input parameters to uncertainty in the system (e.g., radionuclide migration) via a Monte Carlo analysis.

Once project costs (or benefits) are quantified, one can estimate the expected value of perfect information (EVPI). Although the EVPI is not used directly in the VOIA to make a decision, it provides useful information on the value of completely eliminating uncertainty. In other words it provides an upper bound on data worth. The economic costs include data collection, the losses due to contaminated water, and consequences of making improper decisions. The data collection and value of groundwater are determined based on previous drilling projects performed by the U.S. Department of Energy (DOE), and the value of groundwater is determined based on recent sales of groundwater rights. At Project Gnome, the primary consequences of an inadequate understanding of the plume include litigation costs, regulatory fines, and purchase of water to replace that contaminated by radionuclides. Since these costs are difficult to quantify, this analysis relies on statistical protocols used at the Nevada Test Site. In that case, DOE and State of Nevada regulators agreed to use the 95-percent confidence interval when making decisions about radionuclide migration. If the decision maker's confidence level is known a priori, then one can easily calculate the expected cost of failure.

Since obtaining perfect information is nearly impossible, the expected value of sample information (EVSI) represents the more relevant measure in a VOIA. The proposed data collection activity needs to be evaluated prior to the calculation of the EVSI, requiring what is known as a preposterior analysis. This analysis is essentially the process of hypothetically collecting data according to the constraints of the prior information. The process is repeated hundreds to thousands of times via Monte Carlo analysis to determine the outcome (i.e., how the plume migrates). The exact details of the Monte Carlo analysis can become complicated depending on the investigation.

This VOIA analysis relies heavily on the predictions of radionuclide migration as calculated from a numerical groundwater flow and transport model. An analysis of model prediction uncertainty is essentially the basis for determining the value of new information. There are a number of facets of a groundwater flow and transport model that contribute uncertainty to transport predictions. Key among these are properties that control the rate of groundwater flow, such as magnitude of hydraulic gradient, hydraulic conductivity, and 
effective porosity, and properties that control contaminant movement within the groundwater field, such as source location and release characteristics, sorption, and matrix diffusion.

At the Gnome site, the primary uncertainty of concern for estimating the volume of water impacted by the tracer test is the unknown spatial distribution of hydraulic conductivity. Though hydraulic head data are limited and there is uncertainty in the direction of groundwater flow from the site (whether more southerly as determined for the WIPP area, or more westerly as indicated for Nash Draw), the magnitude of the gradient is constrained by the ultimate downgradient discharge point (the Pecos River) and measurements of hydraulic head. Effective porosity is often identified as a critical uncertainty for estimates of contaminant transport. For Gnome, a tracer test (the only practical means of determining effective porosity in the field) has already been conducted, and additional tracer test results are available from WIPP. In this unusual circumstance, the porosity is well characterized for practical purposes. Similarly, the Gnome tracer test and subsequent monitoring data constrain the retardation processes and characteristics of a transport analysis.

In contrast to the above, hydraulic conductivity $(K)$ remains uncertain when calculating groundwater velocity. Work at the WIPP Site has identified a very large range in $K$ within the Culebra Dolomite (transmissivity varies over six orders of magnitude near the WIPP Site), and determined a complex spatial pattern related to geologic and structural characteristics (Holt and Powers, 1988; Holt et al., 2005). Considerable characterization resources have been devoted at WIPP to drilling and testing wells for $K$ (extensive work summarized, with detailed references, in DOE [2009]), geologic studies of sedimentation and post-depositional processes affecting K (Holt and Powers, 1988; Powers and Holt, 2000; Powers et al., 2006), and analysis and modeling of the spatial distribution of $K$ (Hart et al., 2009). As a result, the focus of this VOIA is to determine if additional characterization of $K$ is needed to support long-term management decisions for the Gnome site.

The analysis framework is similar to that of other VOIAs related to environmental risk (James and Freeze, 1993; James and Gorelick, 1994; Yokota and Thompson, 2004; Feyen and Gorelick, 2005) but with minor modifications to suit the specified decision needs of this project. Unlike the analysis of James and Freeze (1993), this analysis does not address how to make a decision on various design alternatives. For example, Bayesian analysis can be used to determine the most appropriate remediation design given uncertainties in the subsurface environment. Since natural attenuation is the likely remediation for radionuclides at Gnome, this analysis focuses solely on future data collection needs.

\section{Analysis Framework}

There are four main components to this VOIA:

1. Determine the costs associated with collecting additional hydraulic conductivity information and the costs associated with groundwater contamination.

2. Calculate the prior uncertainty in the contamination volume given the information that is currently available.

3. Calculate the expected value of perfect information (EVPI) to determine the maximum improvement that could be gained by collecting perfect information.

4. Calculate the expected value of sample information (EVSI) to determine if additional information is cost-beneficial and to optimize how data are collected. 
A cost estimate was prepared for a hydraulic conductivity measurement. Each hydraulic conductivity measurement would require drilling a new well into the Culebra dolomite and conducting a seven-day pumping test. Using cost information from previous drilling efforts provided by drilling companies, the costs for various numbers of wells are provided in Table 2. A simple linear regression was used to determine the cost $(C)$ of collecting more than four hydraulic conductivity measurements

$$
C=514457 N_{w}+61035
$$

where $N_{w}$ is the number of hydraulic conductivity measurements.

Table 2. Cost per well for hydraulic characterization.

\begin{tabular}{cc}
\hline \# Wells & Cost \\
\hline 1 & $\$ 579,719$ \\
2 & $\$ 1,088,002$ \\
3 & $\$ 1,595,620$ \\
4 & $\$ 2,125,371$ \\
\hline
\end{tabular}

Since radionuclide contamination cannot be remediated effectively, the costs associated with the contamination volume are those associated with the value of the water. According to Brookshire et al. (2002), the value of water has increased during the last 10 to 15 years. Over the period 1999 to 2002 , the value of water was determined to be $\$ 4.05 / \mathrm{m}^{3}$. Because of poor water quality (i.e., high total dissolved solids) at the Gnome site, the value of water is expected to be less than the standard rate. Therefore, the value of water at the site is reduced to $\$ 1.14 / \mathrm{m}^{3}$ in consideration of the poor quality.

Although the project costs are partially dependent on the estimated value of water, the VOIA results (expected value of sample information) are less sensitive to this estimate. A sensitivity calculation of the expected value of sample information was done by assuming that the value of water was actually $\$ 4.05 / \mathrm{m}^{3}$. The results indicate that a fourfold increase in the value of water had only a six percent increase in the expected value of sample information, which isn't enough to alter the conclusions of the study.

If one assumes that the costs associated with the contaminant plume were paid in the near future, then the time value of money can be ignored. The project costs $\left(\Phi_{\text {prior }}\right)$ given the current state of knowledge (prior) can then be calculated as the sum of the costs associated with the contaminated water and the risks associated with not delineating all potential radionuclide migration paths (Freeze et al., 1990, 1992)

$$
\Phi_{\text {prior }}=C_{w}+P_{f} C_{f} \gamma\left(C_{f}\right)
$$

In the above equation, $C_{w}$ represents the cost associated with the volume of water that is deemed unacceptable for pumping purposes, $P_{f}$ is the probability of failure, which is the probability of contamination outside of the defined contaminated area, and $C_{f}$ is the cost associated with finding contamination outside of the contaminated area. The costs associated with failure are more difficult to quantify but include litigation costs, regulatory penalties, and the value of water. For the purposes of this analysis, these costs are assumed to be related 
to the volume of water contaminated outside of the defined contaminated area and this assessment is provided in the next section. For a risk-neutral decision maker, the utility function $\gamma\left(C_{f}\right)$ can be taken equal to unity.

The assessment of the prior uncertainty is calculated via a Monte Carlo analysis using the existing conditioning data. Multiple realizations are simulated for the flow and transport model and likelihood that ${ }^{90} \mathrm{Sr}$ will exceed the MCL is calculated for every finite-difference cell in the model domain. Since each model realization is equiprobable, one can calculate the probability of failure that the ${ }^{90} \mathrm{Sr}$ concentration will exceed the MCL as

$$
P_{f}=\sum_{n=1}^{N_{r}} \frac{i_{n}}{N_{r}}
$$

where $i_{n}$ is a binary variable that describes whether the maximum simulated concentration exceeded the MCL $\left(i_{n}=1\right)$ or did not exceed the $\operatorname{MCL}\left(i_{n}=0\right)$ for a particular realization $n$, and $N_{r}$ is the total number of realizations used in the Monte Carlo analysis.

To determine the prior project costs (Equation [3]), one needs to define the spatial extent of the contaminated area and estimate the costs of failure, $C_{f}$. Typically, this is done by predefining a confidence level $\alpha$ (e.g., 95 percent), and then calculating the volume of water for all cells for which $P_{f} \geq 1-\alpha$ (Pohll et al., 2003). For the purposes of this analysis, a confidence level of 95 percent is adopted, which is consistent with other analyses of contaminant areas (Pohll et al., 2003). If the cost of failure were known, one could expand or contract the defined contaminant area until the project costs were minimized. In other words, one would select a confidence interval that minimizes the expected project costs. In this study, one would take advantage of the fact that the confidence level has already been determined and adjust the cost of failure $\left(C_{f}\right)$ until the minimum project costs are achieved at a 95-percent confidence level.

The next step is to calculate the expected EVPI. The EVPI represents the estimated value if the hydraulic conductivity were sampled exhaustively (i.e., hydraulic conductivity were known everywhere within the model domain). It represents the maximum improvement that can be achieved by reducing the uncertainty to zero. In other words, it represents an estimate of the maximum budget that should be spent on exploration (James and Gorelick, 1994). The value of perfect information (VPI) is calculated as the difference between the prior project costs and the costs associated with knowing the exact extent of the radionuclide plume. Since the spatial extent of the plume is not known, one can only estimate the VPI by taking the expectation (i.e., average) over all equiprobable Monte Carlo realizations

$$
E V P I=E\left(\Phi_{\text {prior }}-\Phi_{\text {true }}\right)=\Phi_{\text {prior }}-\sum_{n=1}^{N_{r}} \frac{\Phi_{n}}{N_{r}}
$$

where $\Phi_{n}$ is the cost related to the plume associated with realization $n$. 
Since sampling programs are not able to reduce uncertainty to zero, the expected value of sample information (EVSI) represents a more relevant measure of information value. Calculating the EVSI requires what is known as a preposterior analysis, which implies making an estimate of the value of information prior to actually making the measurements. The preposterior analysis relies on Bayesian theory or Bayesian updating over all possible configurations of the hydraulic conductivity field. Mathematically, the EVSI is represented as (James and Freeze, 1993)

$$
\mathrm{EVSI}=\Phi_{\text {prior }}-\mathrm{E}\left(\Phi^{\prime} \mid \mathrm{K}(\mathrm{b})\right)
$$

where $\Phi_{\text {prior }}$ is the expected project costs prior to collecting additional hydraulic conductivity information, and $E\left(\Phi^{\prime} \mid K(b)\right)$ is the expected project costs based on collecting new hydraulic conductivity samples $K(b)$. Therefore, the EVSI is simply the expected decrease in project costs given new sample information on hydraulic conductivity.

The algorithm used for calculating the EVSI is shown in Figure 13. Again, the EVSI is based on an expectation since various outcomes or measurements of hydraulic conductivity at a sample location are possible. These outcomes are easily determined via a Monte Carlo analysis by selecting a sample location and then using the sequential Gaussian simulation algorithm to generate multiple $\left(N_{r}\right)$ random samples of hydraulic conductivity at that location. For each realization, the random hydraulic conductivity is used as conditioning data for a new suite of simulations. Each suite requires the simulation of multiple $\left(M_{r}\right)$ realizations to generate a hydraulic conductivity field using SGS, solving the flow problem, and then calculating radionuclide migration. The $M_{r}$ realizations are used to calculate the probability that ${ }^{90} \mathrm{Sr}$ will exceed the MCL everywhere within the model domain. These probabilities are used with Equation (3) to calculate the project costs, which are then averaged over all $N_{r}$ realizations to calculate the expected project costs $E\left(\Phi^{\prime} \mid K(b)\right)$ given new hydraulic conductivity information. Using Equation (6), the EVSI can be calculated for this sample location. 


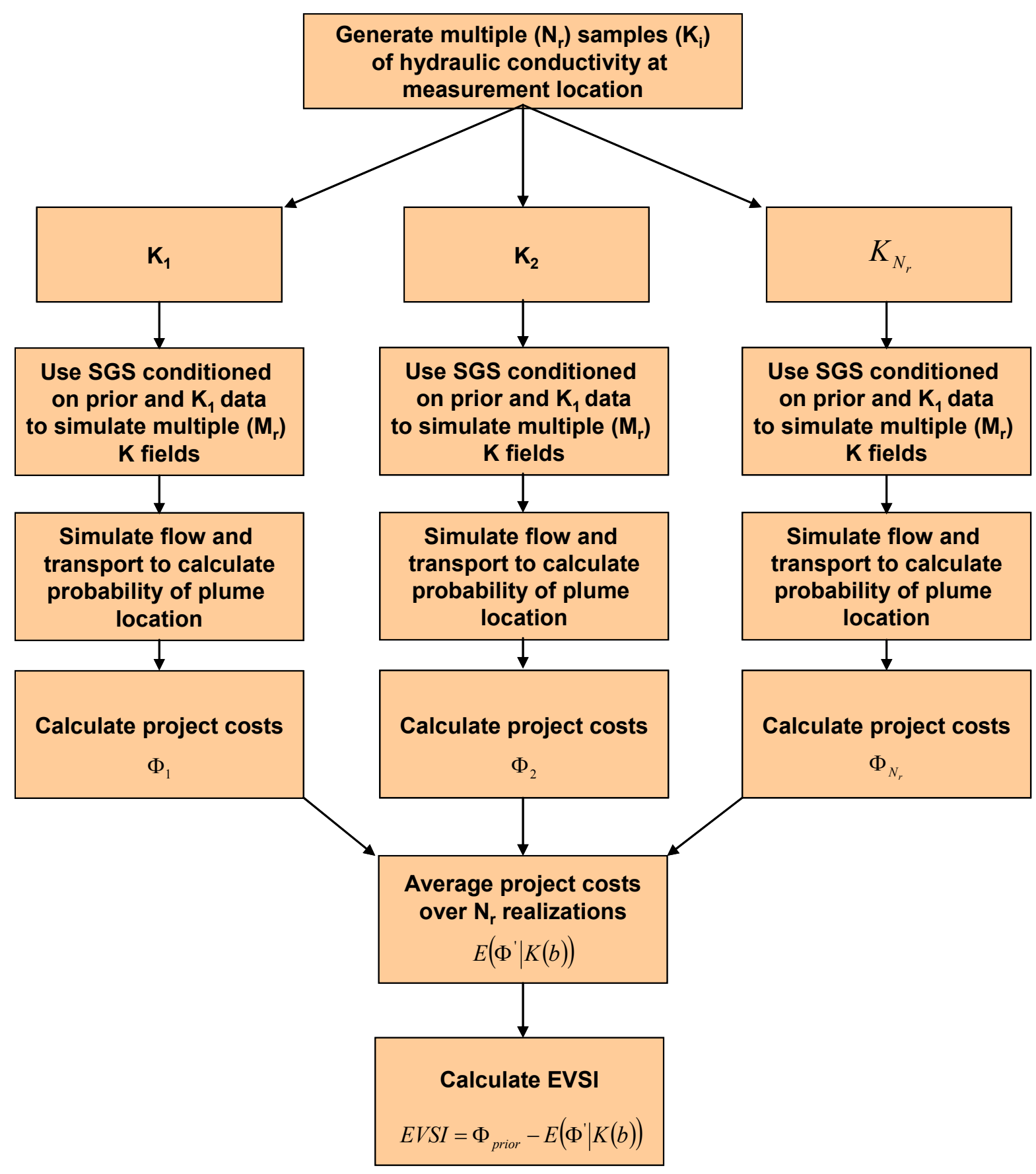

Figure 13. Monte Carlo algorithm for the EVSI analysis.

The above calculation of EVSI is for a single measurement location, but one also needs to determine the location that will lead to the greatest reduction in project costs.

Therefore, the EVSI is calculated at multiple measurement locations and the location with the largest EVSI is selected. Likewise, the EVSI is calculated for various sampling regimes that contain multiple measurements of hydraulic conductivity. 


\section{Prior Uncertainty}

A total of 10,000 Monte Carlo realizations were simulated to determine the spatial distribution for the probability that the ${ }^{90} \mathrm{Sr}$ concentration will exceed the MCL through March 17, 2963. The probability map, which was calculated using Equation (4), is shown in Figure 14. Note that a logarithmic color scale is used to represent the probabilities.

\section{Prior Project Costs}

The project costs are dependent on the costs associated with failure and the confidence level chosen to define the contaminant area. Given a fixed cost of water within the specified contaminant area of $\$ 1.14 / \mathrm{m}^{3}$, one could select a level of confidence to determine the amount of water and the associated cost of removing this water from groundwater production. For example, if a 95-percent confidence level is chosen (meaning we are 95 percent confident that contamination above the MCL is contained within the boundary, and that there is only a 5 percent probability of contamination occurring beyond the boundary), then pumping would be restricted from 220 hectares as shown in Figure 14. This represents approximately 2.5 million cubic meters of water or $\$ 2.9$ million. Since the future plume location is not known, one also has to account for the costs associated with the risk that the plume may extend beyond the contamination area as defined by the 95-percent confidence level. In other words, one has to calculate the costs associated with not selecting a larger confidence level.

Although the cost of failure is not known and is difficult to quantify, we can calculate it based on an assumption that the decision maker will assume a 5 percent risk or less (95-percent confidence level). Figure 15 shows the expected project costs versus confidence level for three different costs of failure. As expected, the minimum cost associated with each curve shifts: with lower cost of failure, minimum cost occurs at lower confidence intervals, with higher cost of failure, minimum cost occurs at higher confidence intervals. Intuitively this makes sense, because one would be more conservative if the costs associated with failure are larger.

For the purposes of this analysis, the red curve was chosen at a cost of failure of $\$ 22.80 / \mathrm{m}^{3}$ because it yielded a confidence level of 95 percent, which is the standard developed for these types of decisions. It is important to note that the cost of failure is twenty times that of the assigned value of water and is meant to represent potential litigation costs, regulatory fines, and purchase of water to replace that contaminated by ${ }^{90} \mathrm{Sr}$. 


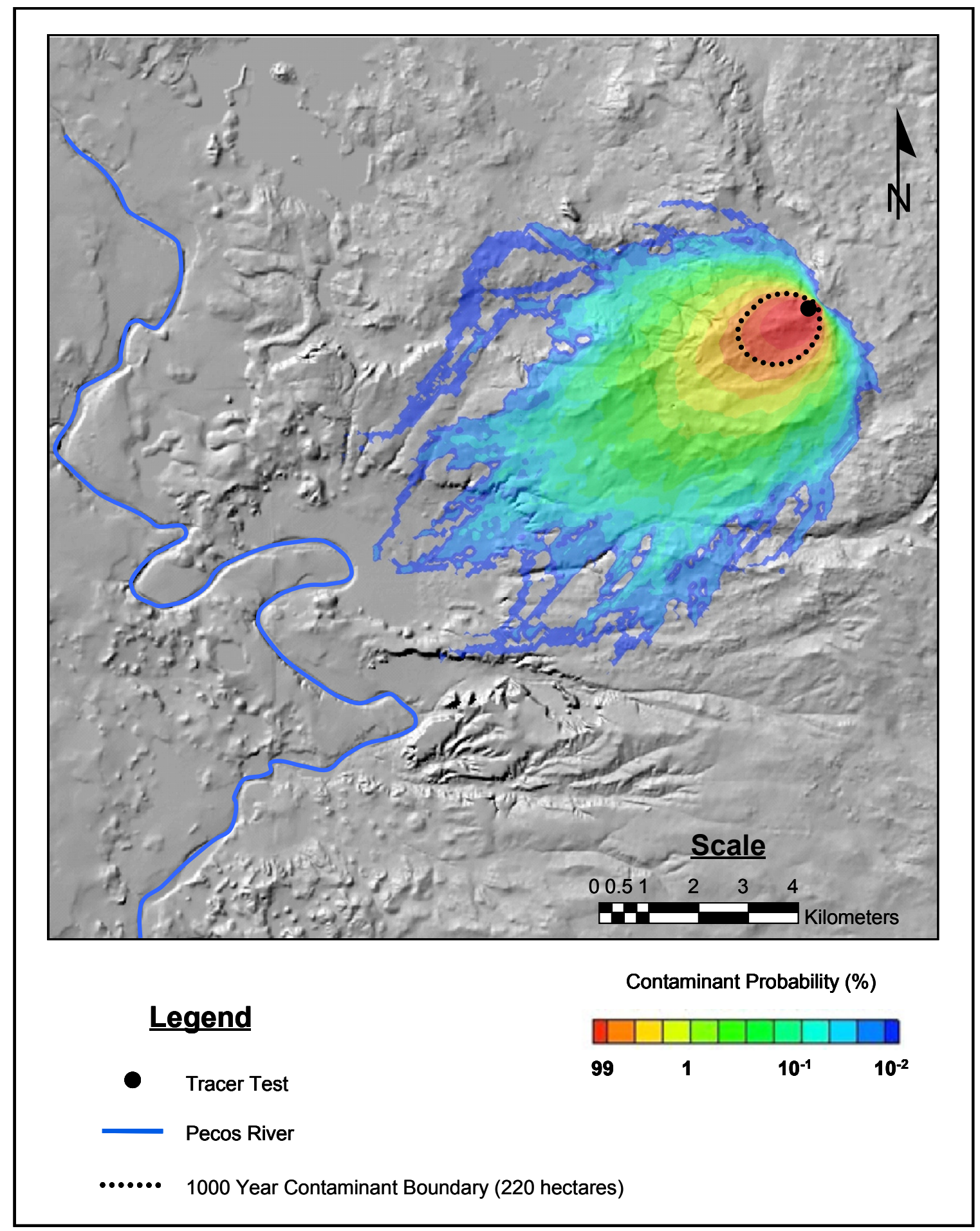

Figure 14. Probability map for ${ }^{90} \mathrm{Sr}$ contaminant plume (1,000-year simulation). 


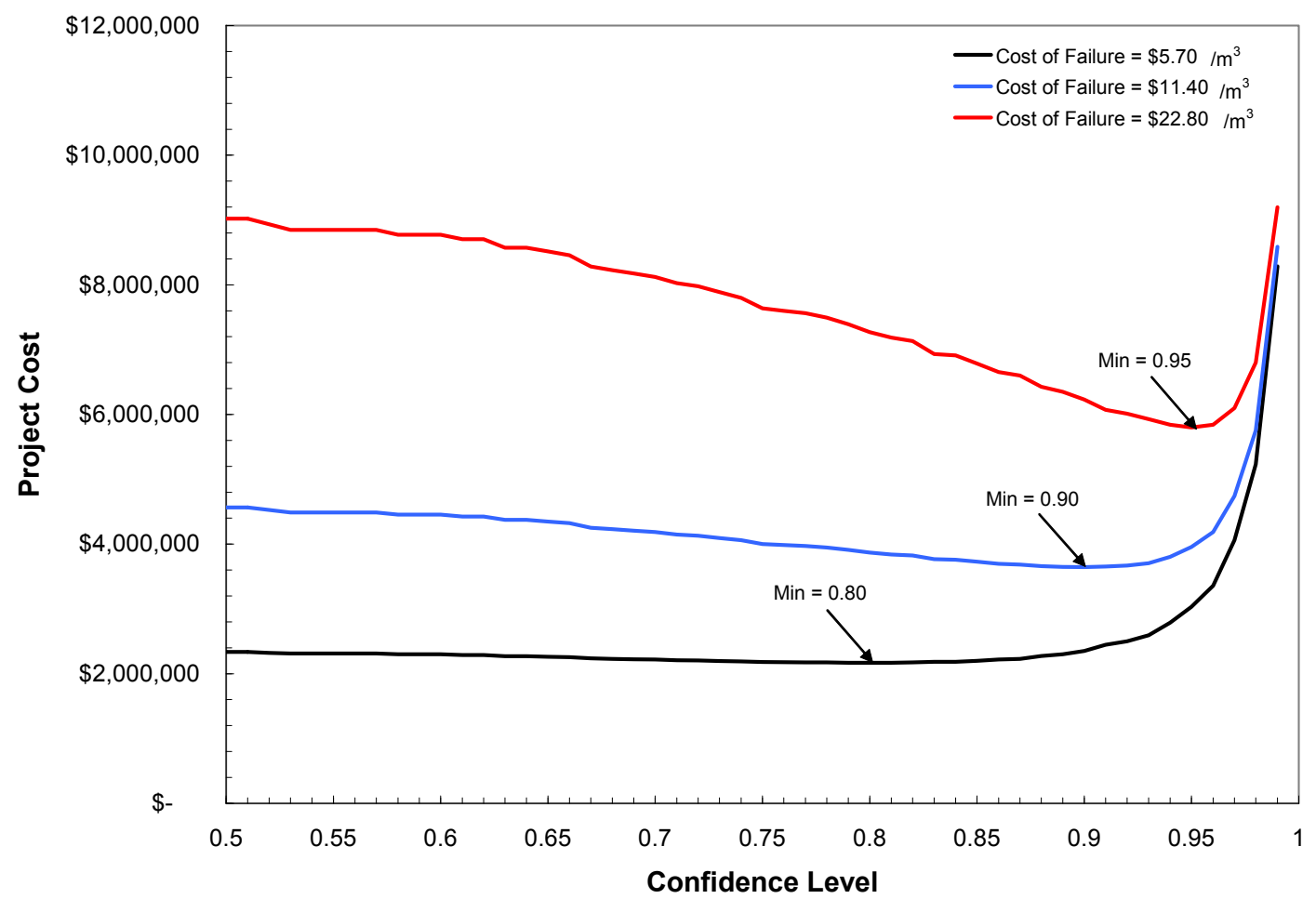

Figure 15. Relationship between selected level of confidence and total project costs for three values of failure cost.

The expected project cost given currently available information and selecting a 95-percent level of confidence is $\$ 5,986,000$. This estimate is based on 10,000 Monte Carlo realizations. Another suite of simulations were tested to determine the impact of the number of realizations on the estimate of project cost. One hundred Monte Carlo suites were simulated, with each having 500 realizations for a total of 50,000 simulations. The project cost was calculated for each of the 100 suites to determine the variability of the results while using a smaller (500) number of realizations. The results are presented in the form of a histogram in Figure 16. The mean project cost is $\$ 6,108,000$ and the standard deviation is $\$ 391,000$. Given that the distribution can be approximated by a normal distribution, the 95 -percent confidence interval ranges between $\$ 5,342,000$ and $\$ 6,874,000$. The estimated project cost using 10,000 realizations falls within one standard deviation of the estimate using 500 realizations. These results indicate that there will be some loss of accuracy when using fewer realizations. 


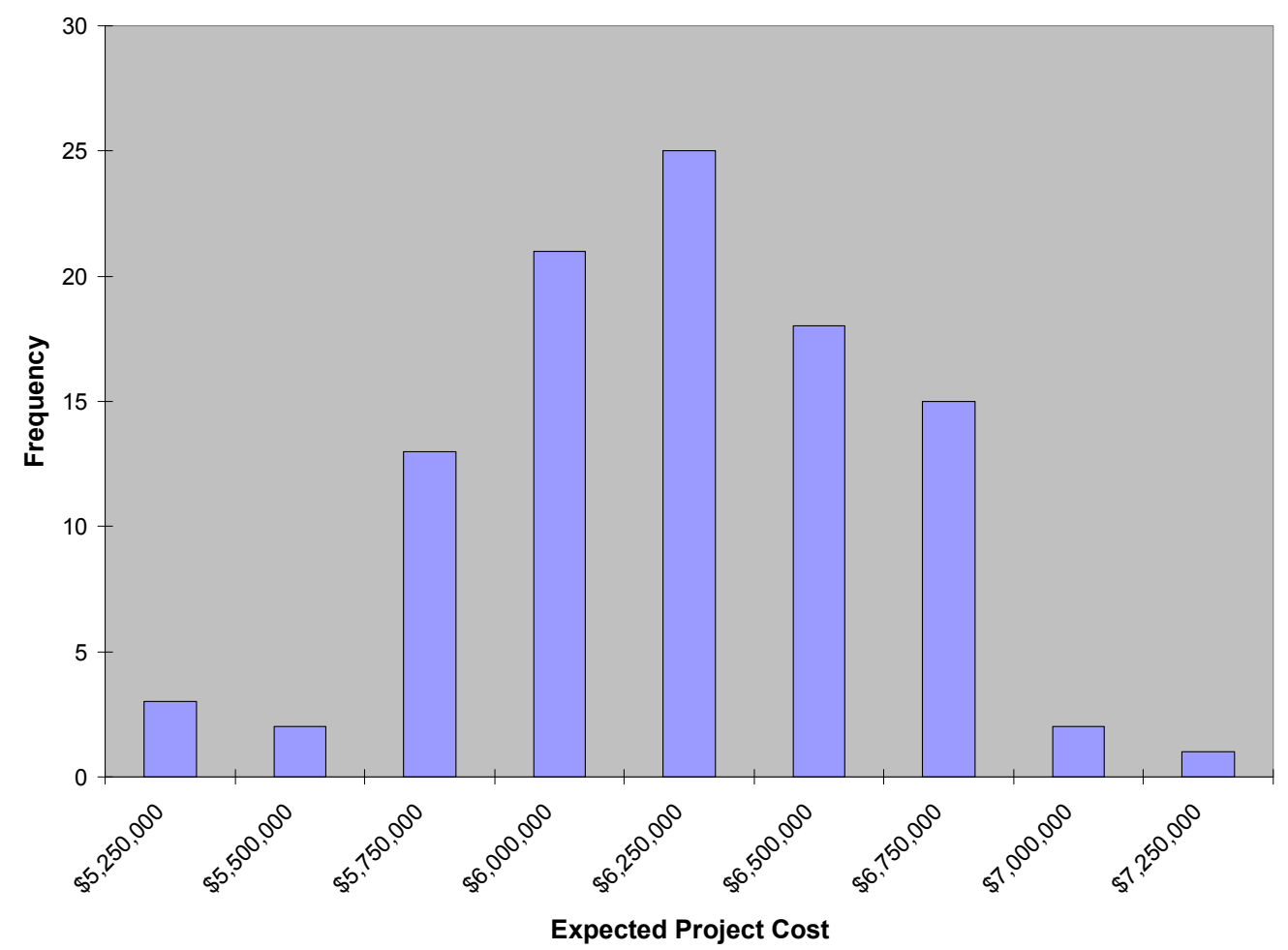

Figure 16. Histogram of expected project cost using 500 Monte Carlo realizations.

\section{Value of Perfect Information}

The EVPI is calculated as the difference between the prior project cost and the average project cost associated with multiple equiprobable realizations of the plume migration as given in Equation (5). The average project cost $\left(\sum_{n=1}^{N_{p}} \frac{\Phi_{n}}{N_{p}}\right)$ as calculated over 10,000 realizations is $\$ 543,000$. Therefore, the computation of EVPI is simply $\$ 5,986,000-\$ 543,000=\$ 5,443,000$. This is the maximum budget that should be spent on data collection. The EVPI equates to a maximum of 10 wells that may be drilled. This doesn't mean that 10 wells should be drilled, since the uncertainty reduction obtained from 10 measurements of hydraulic conductivity may not be on par with an exhaustive sampling strategy.

\section{Value of Sample Information}

Multiple sampling scenarios were simulated to determine how many wells should be drilled and sampled for hydraulic conductivity. Table 3 outlines the sampling scenarios, the number of wells being measured and how many well combinations were used in the analysis. The sample locations were chosen based on the results of the prior uncertainty simulation (see Figure 14). The general plume was examined and wells were located such that there was coverage throughout the potential migration area. For example, in scenario A, it was assumed that one new well would be drilled and a pumping test be performed to determine the hydraulic conductivity. Likewise, a total of 12 well locations were simulated to determine the 
optimal well location. In scenario B, it was assumed that two hydraulic conductivity measurements were obtained and five sets of two wells each were simulated. The locations of the measurement points are shown in Figure 17 for each of the sampling scenarios.

Table 3. Description of characterization scenarios.

\begin{tabular}{ccc}
\hline Sampling Scenario & Number of Measurements & Well Combinations \\
\hline A & 1 & 12 \\
B & 2 & 5 \\
C & 3 & 6 \\
D & 4 & 1 \\
E & 5 & 1 \\
F & 9 & 1 \\
\hline
\end{tabular}

The EVSI results for scenario A are shown in Figure 18. The number next to each point represents the calculated EVSI value (in thousands of dollars). The point with the highest EVSI (located to the northwest of the tracer test) represents the most appropriate sampling location. The EVSI must be greater than the cost of sampling or further characterization should not be done. Given that the cost for a single well is $\$ 579,719$ and the maximum EVSI is $\$ 497,000$, drilling a single well to determine hydraulic conductivity is not recommended.

Table 4 summarizes the results for the remainder of the sampling scenarios. Although increasing the number of hydraulic conductivity measurements increases the EVSI, none of the scenarios produces a positive net benefit. None of the characterization scenarios is cost-beneficial.

Table 4. Expected value of sampling information for the characterization scenarios.

\begin{tabular}{crrrrrrr}
\hline & Case A & Case B & Case C & Case D & Case E & Case F \\
\hline EVSI & $\$ 497,000$ & $\$ 426,000$ & $\$ 523,000$ & $\$ 588,000$ & $\$ 630,000$ & $\$ 819,000$ \\
Number of Wells & 1 & 2 & 3 & 4 & 5 & 9 \\
Sampling Cost & $\$ 575,492$ & $\$ 1,089,949$ & $\$ 1,604,406$ & $\$ 2,118,863$ & $\$ 2,633,320$ & $\$ 4,691,148$ \\
Net Benefit & $\$(78,492)$ & $\$(663,949)$ & $\$(1,081,406)$ & $\$(1,530,863)$ & $\$(2,003,320)$ & $\$(3,872,148)$ \\
\hline
\end{tabular}



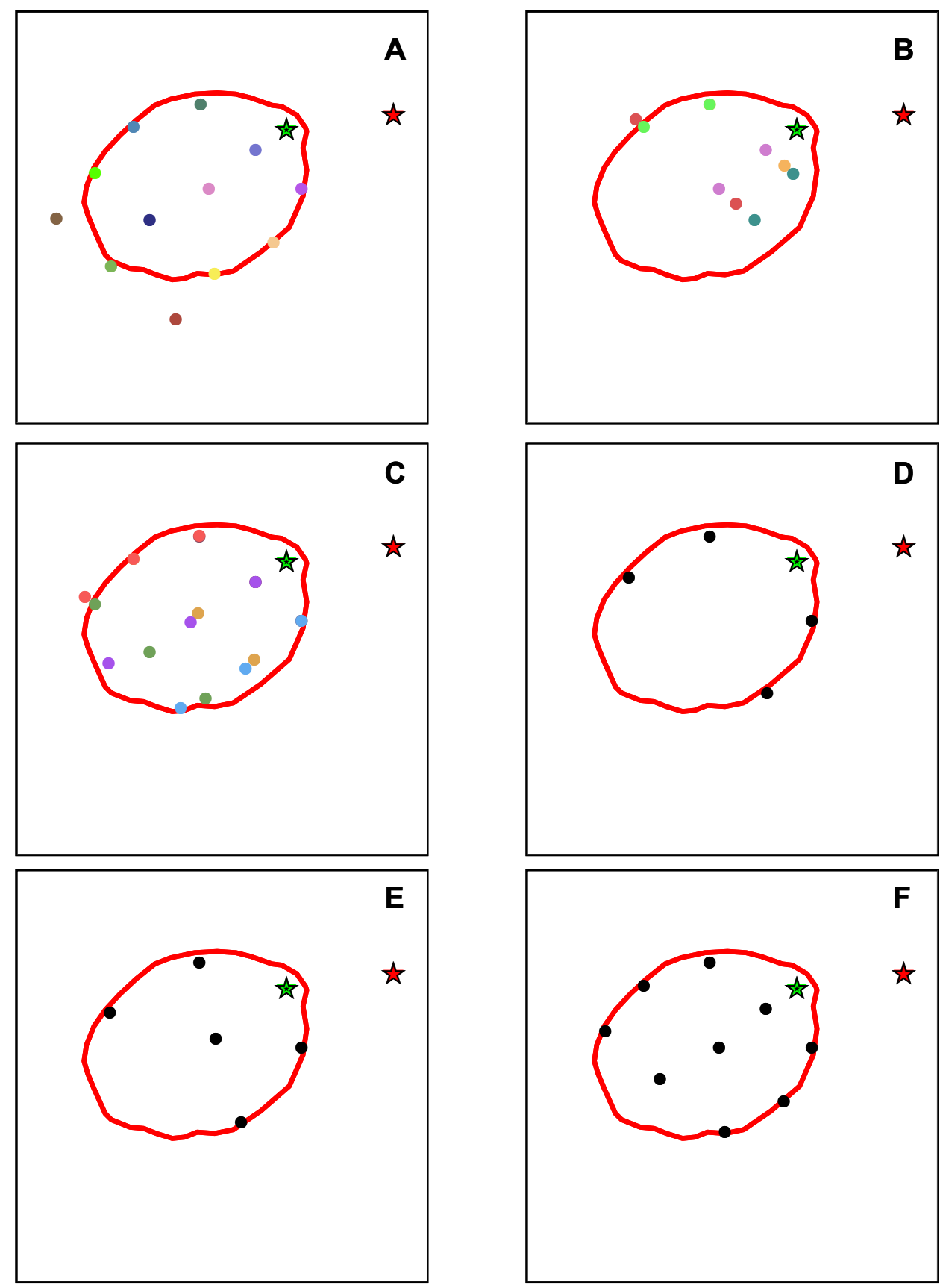

\section{Legend}

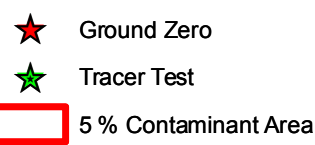

- Hypothetical Sampling Points

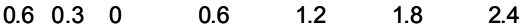

Kilometers

Figure 17. Locations of hydraulic conductivity sampling points for each scenario. Similar colored points represent a sampling set. 

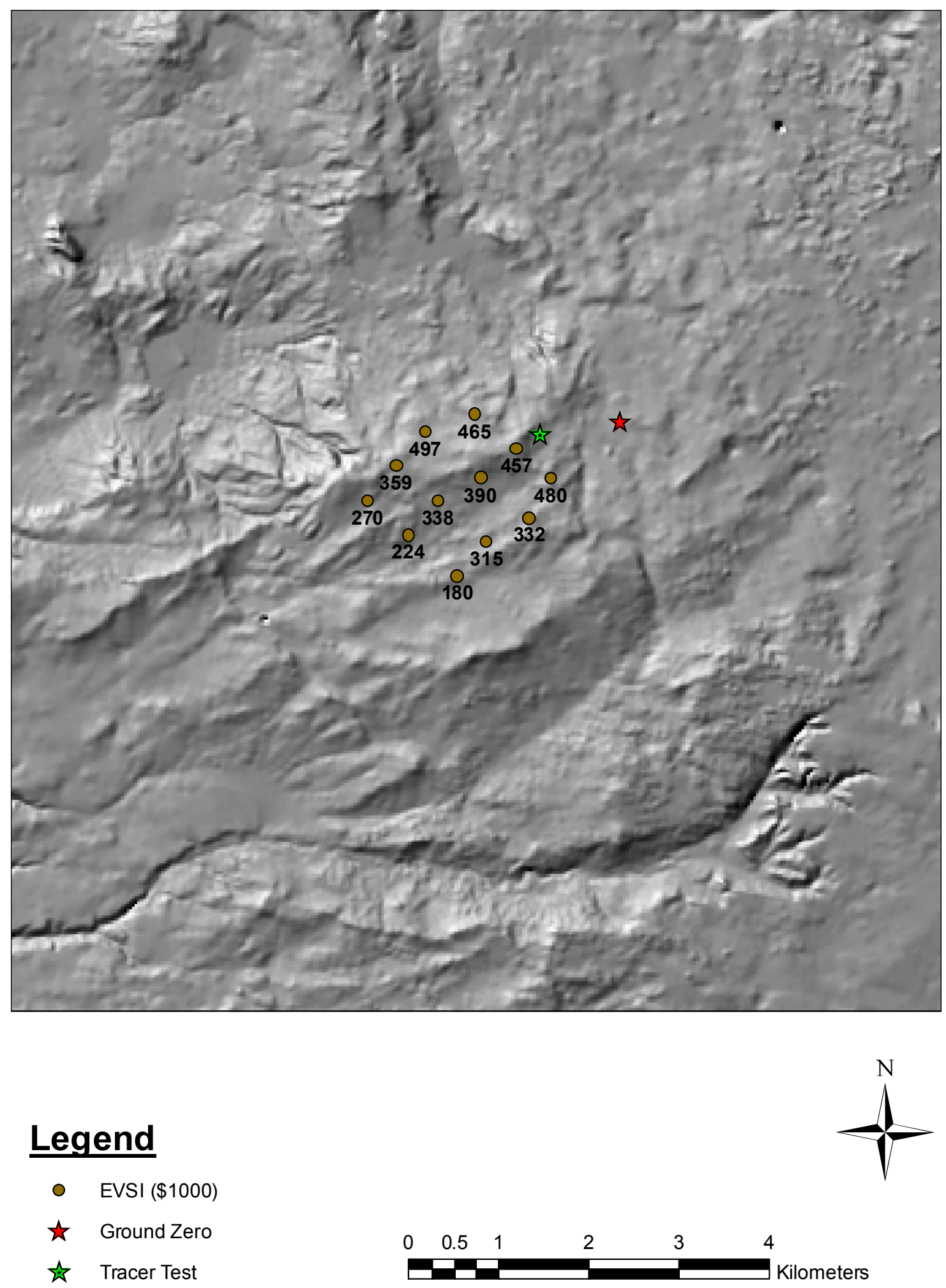

Figure 18. Calculated Expected Value of Sample Information (EVSI) in thousands of dollars for scenario A. 


\section{CONCLUSIONS}

As prescribed in the Site Characterization Work Plan for the Gnome site (DOE, 2002), a quantitative analysis is presented here to weigh the potential value of additional data collection at Gnome against the cost of such field efforts. The objective is to determine if additional characterization data are needed prior to evaluating subsurface intrusion restrictions and determining long-term monitoring.

Bayesian theory is implemented with a groundwater flow and transport model to estimate the volume of affected groundwater for a given confidence interval under existing uncertainty conditions, and the volume after hypothetical data collection activities. These estimates are then assigned a value based on economic factors (both the value of the water and the risk of error in the plume extent), and compared to estimated costs for data collection. Additionally, the optimal locations for data collection are identified.

The groundwater flow and transport model was developed using parameters derived from analysis of the Gnome tracer test itself, from data and analysis developed for the adjacent WIPP site, and from prior model evaluations of Gnome. Evaluation of these information sources led to identification of hydraulic conductivity as the primary data collection target of concern. Other flow and transport parameters were reasonably constrained by previous testing or natural conditions, whereas hydraulic conductivity was found to be a widely varying and important determinant of flow at WIPP. The VOIA thus specifically addressed the benefit of collecting additional hydraulic conductivity data.

Given an assumed cost of water in the Gnome area of $\$ 1.14$ per cubic meter and an assumed cost of failure of $\$ 22.80$ per cubic meter (this includes value of water to replace contaminated water, and costs for litigation and regulatory penalties), the prior project costs are estimated to be $\$ 5,986,000$. Multiple scenarios for characterization were considered, involving numerous hydraulic conductivity measurements at various combinations of assumed new wells. The expected value of sample information was calculated for each scenario by updating the flow and transport analysis based on the assumed new information. The expected value of the sample information in all cases was less than the cost to collect the data. From an economic viewpoint, further characterization of hydraulic conductivity at Gnome is not recommended prior to evaluating subsurface intrusion restrictions and determining long-term monitoring.

Rather than embarking on a site characterization program, the existing information for the Gnome site, augmented by data from WIPP investigations, can be used as a basis for designing a site management and monitoring program. The implementation of this plan will involve drilling and installation of wells, and the new information gathered from these wells will be critical for reducing uncertainty in contaminant migration predictions and building confidence in site management. For example, though the VOIA did not find it cost effective to drill and test a well for characterizing hydraulic conductivity, the minimal additional cost to perform a hydraulic test in a newly installed monitoring well is small relative to the information gain. The key difference is that the location of the well should be identified based on the monitoring objectives, not characterization issues. Additionally, it should be noted that the VOIA is insensitive to the direction of groundwater flow, whereas that is a critical element of detection monitoring that requires more investigation. 


\section{REFERENCES}

Altman, S.J., L.C. Meigs, T.L. Jones, and S.A. McKenna, 2002. Controls of mass recovery rates in single-well injection-withdrawal tracer tests with a single-porosity, heterogeneous conceptualization.

Beauheim, R.L., 1987. Interpretations of single-well hydraulic tests conducted at and near the Waste Isolation Pilot Plant (WIPP) site, 1983-1987, Rep. SAND87-0039, Sandia Natl. Lab., Albuquerque, N. M.

Beauheim, R.L., 1989. Interpretation of H-11b4 hydraulic tests and the H-11 multipad pumping test of the Culebra dolomite at the Waste Isolation Pilot Plant (WIPP) site, Rep. SAND89-0536, Sandia Natl. Lab., Albuquerque, N.M.

Beetem, W.A. and C.G. Angelo, 1964. Tracer study at Project Gnome site, near Carlsbad, New Mexico: Background information. Technical Letter: Carlsbad Hydrology-2, U.S. Geological Survey.

Brookshire, D.S., M. Ewers, P. Ganderton, and J. Little, 2002. Western Water Market Prices and the Economic Value of Water, SAHRA annual meeting, Tucson AZ, February 25, 2002, 2) AERE World Congress 2002, Monterey, CA.

Cauffman, T.L., A.M. LaVenue, and J.P. McCord, 1990. Ground-Water Flow Modeling of the Culebra Dolomite. Volume II: Database, SAND90-7068/2, prepared for Sandia National Laboratories by INTERA Technologies, Inc.

Conrad, S., M. Goodrich, and T. Feeney, 1998. A Preliminary Human Health Risk Assessment of the Gnome Site, New Mexico, Sandia National Laboratories. Contractor Report SAND89-7068/2.

Cooper, J.B. and V.M. Glanzman, 1971. Geohydrology-1, completion and Development of USGS Test Hole 8 and USGS Test Hole 4, Carlsbad Hydrologic Studies, Eddy County, New Mexico, U.S. Geological Survey, Denver, CO.

Cooper, J.B., 1962a. Ground-Water Investigations of the Project Gnome Area, Eddy and Lea Counties, New Mexico, Washington, D.C., U.S. Geological Survey, TEI-802.

Cooper, J.B., 1962b. Ground Water. In Atomic Energy Commission, 1962, Final Report, Hydrologic and Geologic Studies (PNE-130F), pp. 112-136.

Corbet, T.F. and P.M. Knupp, 1996. The Role of Regional Groundwater Flow in the Hydrogeology of the Culebra Member of the Rustler Formation at the Waste Isolation Pilot Plant (WIPP), Southeastern New Mexico.

Deutsch, C.V. and A.G. Journel, 1992. GSLIB - Geostatistical Software Library and User's Guide, Oxford University Press, New York.

Earman, S., J. Chapman, K. Pohlmann, and R. Andricevic, 1996. Assessment of Hydrologic Transport of Radionuclides from the Gnome Underground Nuclear Test Site, New Mexico. Desert Research Institute, Water Resources Center Publication No. 45143. 
Farnham, I.M., L.C. Meigs, M.E. Dominguez, K. Lindley, J.M. Daniels, and K.J.

Stetzenbach, 2000. Evaluation of tracers used for the WIPP tracer tests, in Interpretations of Tracer Tests Performed in the Culebra Dolomite at the Waste Isolation Pilot Plant Site, edited by L. C. Meigs, R. L. Beauheim, and T. L. Jones, pp. 273-289, Rep. SAND973109, Sandia Natl. Lab., Albuquerque, N.M.

Freeze, R.A., B. James, J. Massmann, T. Sperling, and L. Smith, 1992. Hydrogeological decision analysis, 4 . The concept of data worth and its use in the development of site investigation strategies. Ground Water 30(4), 574-588.

Freeze, R.A., J. Massmann, L. Smith, T. Sperling, and B. James, 1990. Hydrogeological decision analysis, 1. A Framework. Ground Water 28(5) 738-766.

Gard, L.M., Jr., 1968. Geologic Studies, Project Gnome, Eddy County, New Mexico, U.S. Geological Survey Professional Paper 589, Washington, D.C.

Gardner, M.C. and J.J. Sigalove, 1970. Evaluation of the Project Gnome/Coach Site, Carlsbad, New Mexico for Disposition, Including Identification of Restrictions, NVO1229-106, Part I. Teledyne Isotopes, Palo Alto, CA 44 pp., AT(29-2)-1229.

Grove, D.B. and W.A. Beetem, 1971. Porosity and dispersion calculations for a fractured carbonate aquifer using the two well tracer method. Water Resources Research 7(1), 128-134.

Haggerty, R., S.W. Flemming, L.C. Meigs, and S.A. McKenna, 2001. Tracer Tests in a fractured dolomite 2. Analysis of mass transfer in a single-well injection-withdrawal tests. Water Resources Research 37(5) 1129-1142.

Haggerty, R., S.A. McKenna, and L.C. Meigs, 2000. On the late-time behavior of tracer test breakthrough curves. Water Resources Research 36(12), 3467-3479.

Haggerty, R., 2000. Development of late-time slopes on log-log breakthrough curves after a pulse-type injection for the case of infinite matrix blocks, in Interpretations of Tracer Tests Performed in the Culebra Dolomite at the Waste Isolation Pilot Plant Site, edited by L. C. Meigs, R. L. Beauheim, and T. L. Jones, Append. K, pp. 305- 307, Rep. SAND973109, Sandia Natl. Lab., Albuquerque, N.M.

Harbaugh, A.W., 2005. MODFLOW-2005, the U.S. Geological Survey modular groundwater model -- the Ground-Water Flow Process: U.S. Geological Survey Techniques and Methods 6-A16.

Hart, D.B., R.L. Beauheim, and S.A. McKenna, 2009. Analysis Report for Task 7 of AP-114: Calibration of Culebra Transmissivity Fields. Sandia National Laboratories WIPP Recods Center, Carlsbad, N.M.

Hart, D.B., R.M. Holt, and S.A. McKenna, 2008. Analysis Report for Task 5 of AP-114: Generation of Revised Base Transmissivity Fields. ERMS\# 541153, Sandia National Laboratories WIPP Records Center, Carlsbad, NM.

Haug, A., V.A. Kelley, A.M. LaVenue, and J.F. Pickens, 1987. Modeling of Ground-Water Flow in the Culebra Dolomite at the Waste Isolation Pilot Plant (WIPP) Site: Interim Report, SAND86-7167, Sandia National Laboratories. 
Holt, R.M., 1997. Conceptual Model for Transport Processes in the Culebra Dolomite Member, Rustler Formation, Sandia National Laboratories Report SAND97-0194.

Holt, R.M., R.L. Beauheim, and D.W. Powers. 2005. "Predicting Fractured Zones in the Culebra Dolomite." Dynamics of Fluids and Transport in Fractured Rock (pp. 103-16). B. Faybishenko, P.A. Witherspoon, and J. Gale, eds. Geophysical Monograph Series, 162. Washington, DC: American Geophysical Union.

Holt, R.M. and D.W. Powers. 1988. Facies Variability and Post-Depositional Alteration Within the Rustler Formation in the Vicinity of the Waste Isolation Pilot Plant, Southeastern New Mexico. DOE/WIPP 88-004. ERMS 242145. Carlsbad, NM: U.S. Department of Energy

James, B.R. and R.A. Freeze, 1993. The worth of data in predicting aquitard continuity in hydrogeological design. Water Resources Research 29(7), 2049-2065.

James, B.R. and S.M. Gorelick, 1994. When enough is enough: The worth of monitoring data in aquifer remediation design. Water Resources Research 20(12), 3499-3513.

Jones, T.L., V.A. Kelley, J.F. Pickens, and D.T. Upton, 1992. Integration of Interpretation Results of Tracer Tests Performed in the Culebra Dolomite at the Waste Isolation Pilot Plant Site. SAND92-1579, Sandia National Laboratories.

Jones, T.L. and S.J. Altman, 2000. Effects of sorption on tracer breakthrough for a SWIW test, in Interpretations of Tracer Tests Performed in the Culebra Dolomite at the Waste Isolation Pilot Plant Site, edited by L. C. Meigs, R. L. Beauheim, and T. L. Jones, Append. O, pp. 321 - 325, Rep. SAND97-3109, Sandia Natl. Lab., Albuquerque, N.M.

Jones, T.L. and L.C. Meigs, 2000. Calculation of diffusion of tracer trapped in the borehole during injection, in Interpretations of Tracer Tests Performed in the Culebra Dolomite at the Waste Isolation Pilot Plant Site, edited by L. C. Meigs, R. L. Beauheim, and T.L. Jones, Append. N, pp. 317-320, Rep. SAND97-3109, Sandia Natl. Lab., Albuquerque, N.M.

LaBolle, E.M., 2003. RWHet: Random Walk Particle Model for Simulating Transport in Heterogeneous Permeable Media, Version 3.0, User's Manual and Program Documentation.

Lappin, A.R., 1988. Summary of Site-Characterization Studies Conducted from 1983 through 1987 at the Waste Isolation Plant (WIPP) Site, Southeastern New Mexico. SAND88-0157, Sandia National Laboratories.

Lowenstein, T.K., 1987. Post Burial Alteration of the Permian Rustler Formation Evaporates, WIPP Site, New Mexico: Textural, Stratigraphic, and Chemical Evidence, New Mexico Environmental Evaluation Group, EEG-36.

Lynch, A.W. and R.G. Dosch, 1980. Sorption Coefficients for Radionuclides on Samples from the Water-Bearing Magenta and Culebra Members of the Rustler Formation, SAND80-1064, Sandia National Laboratories. 
McKenna, S.A., 2000. Controls on multiwell convergent-flow tracer-breakthrough-curve tailing for a single-porosity, heterogeneous conceptualization, in Interpretations of Tracer Tests Performed in the Culebra Dolomite at the Waste Isolation Pilot Plant Site, edited by L. C. Meigs, R. L. Beauheim, and T. L. Jones chap. 5, pp. 69- 83, Rep. SAND97-3109, Sandia Natl. Lab., Albuquerque, N.M.

McKenna, S.A., L.C. Meigs, and R. Haggerty, 2001. Tracer tests in a fractured dolomite, 3, Double porosity, multiple-rate mass transfer processes in convergent-flow tracer tests. Water Resources Research 37(5), 1143- 1154.

Meigs, L.C., and R.L. Beauheim, 2001. Tracer tests in a fractured dolomite, 1, Experimental design and observed tracer recoveries. Water Resources Research 37(5), 1113-1128.

Meigs, L.C., R.L. Beauheim, and T.L. Jones, 2000. Experimental design and observed tracer recoveries for the 1995-96 tracer tests, in Interpretations of Tracer Tests Performed In the Culebra Dolomite at the Waste Isolation Pilot Plant Site, edited by L. C. Meigs, R. L. Beauheim, and T. L. Jones, chap. 3, pp. 17- 35, Rep. SAND97-3109, Sandia Natl. Lab., Albuquerque, N.M.

Moench, A.F., 1995. Convergent radial dispersion in a double-porosity aquifer with fracture skin: Analytical solution and application to a field experiment in fractured chalk. Water Resources Research 31(8), 1823-1835.

Ostensen, R.W., 1998. Tracer tests and contaminant transport rates in dual-porosity formations with application to the WIPP. Journal of Hydrology 204, 197-216.

Pohll, G. and K. Pohlmann, 1996. Evaluation of the Radionuclide Tracer Test Conducted at the Project Gnome Underground Nuclear Test Site, New Mexico, Desert Research Institute, Division of Hydrologic Sciences Publication No. 45141.

Pohll, G., K. Pohlmann, J. Daniels, A. Hassan, and J. Chapman. 2003. Contaminant and Compliance Boundaries at the Faultless Underground Nuclear Test. Desert Research Institute, Division of Hydrologic Sciences Publication No. 45196.

Pohlmann, K. and R. Andricevic, 1994. Scoping Calculations for Groundwater Transport of Tritium from the Gnome Site, New Mexico. Desert Research Institute, Water Resources Center Publication No. 45126.

Pohlmann, K., G. Pohll, J. Chapman, A. Hassan, R. Carroll, and C. Shirley, 2002. Modeling of Groundwater Contaminant Boundaries for the Shoal Underground Nuclear Test, Desert Research Institute, Division of Hydrologic Sciences Publication No. 45184.

Powers, D.W., R.L. Beauheim, R.M. Holt, and D.L. Hughes, 2006b. Evaporite Karst Features and Processes at Nash Draw, Eddy County, New Mexico. Caves and Karst of Southeastern New Mexico (pp. 253-65). L. Land, V.W. Lueth, W. Raatz, P. Boston, and D.L. Love, eds. 57th Annual Fall Field Conference Guidebook. Socorro, NM: New Mexico Geological Society.

Powers, D.W. and R.M. Holt, 2000. The Salt that Wasn't There: Mudflat Facies Equivalents to Halite of the Permian Rustler Formation, Southeastern New Mexico. Journal of Sedimentary Research 70: 29-36. 
Reeves, M., V.A Kelley, and J.F. Pickens, 1987. Regional Double-Porosity Solute Transport in the Culebra Dolomite: An Analysis of Parameter Sensitivity and Importance at the Waste Isolation Pilot Plant (WIPP) Site. SAND87-7105, Sandia National Laboratories, Albuquerque, New Mexico, $169 \mathrm{p}$.

Snyder, R.P., 1985. Dissolution of halite and gypsum, and hydration of anhydrite to gypsum, Rustler Formation, in the vicinity of the Waste Isolation Pilot Plant, southeastern New Mexico, U.S. Geological Survey Open-File Report 85-229.

U.S. Department of Energy (DOE), 2002. Site Characterization Work Plan for the GnomeCoach Site, New Mexico. National Nuclear Security Administration, Nevada Operations Office report DOE/NV--689-Rev.1, 126p.

U.S. Department of Energy (DOE), 2004. Surface Corrective Action Investigation Report for the Gnome-Coach Site, New Mexico. National Nuclear Security Administration, Nevada Site Office report DOE/NV--926, 94p.

U.S. Department of Energy (DOE), 2009. Appendix HYDRO-2009 Hydrological Investigations. Title 40 CFR Part 191 Subparts B and C Compliance Recertification Application for the Waste Isolation Pilot Plant, 85p.

U.S. Environmental Protection Agency (EPA), 2000. National Primary Drinking Water Regulations; Radionuclides; Final Rule. 40 CFR 141, Subpart G, Section 141.66 Maximum contaminant levels for radionuclides, Federal Register Vol. 65, No. 236, p. $76707-76753$.

Yokata, F. and K. Thompson, 2004. Value of information literature analysis: A review of applications in health risk assessment. Medical Decision Making 24, 287-298.

Zheng, C. and P.P. Wang, 1999. MT3DMS: A Modular Three-Dimensional Multispecies Transport Model for Simulation of Advection, Dispersion, and Chemical Reactions of Contaminants in Groundwater Systems; Documentation and User's Guide, U.S. Army Corps of Engineers, SERDP-99-1, 220p. 


\section{APPENDIX. COST ESTIMATES FOR FIELD ACTIVITIES}

By Brad Lyles, John Healey, and Jenny Chapman

The DDA identified the following potential data collection activities:

1. Survey existing wells and measure water levels, assuming six well locations.

2. Drill a new well(s) to the Culebra Dolomite (approximately $150 \mathrm{~m}$ below ground surface) to validate geologic structure, measure static water level, and perform a pumping test. Options of drilling one, two, three, and four wells were identified.

The cost estimates for new wells have three components: costs for a prime contractor in charge of the drilling and construction activity, costs for a hydrogeologic subcontractor for oversight of scientific and technical project objectives, and costs for operating subcontractors such as a drilling company and pad construction company. The costs estimates are summarized in Table A-1. Development of each of the cost packages is described below.

Table A-1. Summary of Gnome Drilling and Testing Cost Estimates.

\begin{tabular}{lrrrr}
\hline \multicolumn{1}{c}{ Contractor } & one well & two wells & three wells & four wells \\
\hline Prime & $\$ 283,444$ & $\$ 566,888$ & $\$ 850,331$ & $\$ 1,133,775$ \\
Hydrogeologic & $\$ 107,117$ & $\$ 142,798$ & $\$ 177,814$ & $\$ 234,963$ \\
Operating & $\$ 189,158$ & $\$ 378,316$ & $\$ 567,475$ & $\$ 756,633$ \\
Total & $\$ 579,719$ & $\$ 1,088,002$ & $\$ 1,595,620$ & $\$ 2,125,371$ \\
\hline
\end{tabular}

\section{Prime Contractor Cost Estimate}

Costs for the prime contractor were taken from offsite project baseline costs originally developed by Stoller-Navarro Joint Venture (SNJV) when the offsite projects were part of the DOE environmental management program. The scope of the original estimate was for the installation of three monitoring wells and hydrologic testing at the Gnome Site to evaluate and establish subsurface conditions and validate the groundwater model. The costs for three wells were simply divided by three to derive per well costs for the DDA. It is possible that this underestimates the cost for one or two wells, because some support activities are not expected to scale down (e.g., preparation of a health and safety plan would require about the same amount of effort for one well as for multiple wells).

\section{Prime Contractor Basis of Estimate}

Subsurface field activities will be implemented in accordance with the Corrective Action Investigation Plan and approved project plans. This task comprises the preparation of planning documentation, site preparation, monitoring well installation, site restoration, and development of the well completion reports. Planning documentation includes the contractorspecific requirements, fluid management plans, procurement and management activities, training, and a readiness review prior to mobilization. Site preparation includes the construction of the well pads and sumps and any necessary repairs to the existing roads to allow access to the site. Three monitoring wells will be installed to a depth of $500 \mathrm{ft}$ using an approved drilling method. Well construction will be performed by the drilling subcontractor with the support of a four-person team during program execution. The well pads and sumps 
will be re-graded to restore the site following the groundwater testing. The results and findings of the field program will be documented in the well completion reports. Detailed estimates are derived from past experience and historical costs based on previously implemented and/or proven technologies. Cost estimates were developed using FY 2006 rates.

\section{$\underline{\text { Prime Contractor Assumptions }}$}

- Data Decision Analysis results will recommend the installation of three monitoring wells.

- Maximum depth of the monitoring wells will not exceed $500 \mathrm{ft}$.

- The wells will be designed and constructed as long-term monitoring wells.

- Each of the wells will have the same construction design.

- Each well will be constructed in 15 working days.

- Mobilization and demobilization will require 5 days each.

- Drilling activities will be conducted on a 24-hour per day basis with 2 shifts per day.

- No hazardous and/or radioactive waste will be generated.

\section{$\underline{\text { Prime Contractor Estimate }}$}

The estimate for the task described above, assigning all labor, analytical, travel, and costs in the category of "other" to the prime contractor is $\$ 850,331$. The estimate per well is then $\$ 283,444$, giving $\$ 1,133,775$ as the prime contractor cost for four wells.

\section{Hydrogeologic Subcontractor Cost Estimate}

The cost estimate for the hydrogeologic subcontractor was developed using a bottom-up approach and the Desert Research Institute's (DRI) cost estimating software package that supports DRI cost estimates for DOE work. The scope of work was based on similar work performed during drilling and testing at other offsite nuclear test locations, and involves oversight and participation with the primary focus on meeting technical objectives (as compared to the multiple priorities of health and safety, cost, schedule, etc., of the prime contractor).

\section{Hydrogeologic Subcontractor Basis of Estimate}

It is assumed here that initial modeling and the DDA identify the need for additional subsurface characterization. The basic tasks are: drilling, testing, and sampling of wells. The objectives of the wells may include: 1) provide hydraulic head data to substantiate groundwater flow directions, 2) provide groundwater samples for water quality and site characterization purposes, 3) provide locations to measure hydraulic conductivity, storage, and other aquifer properties as able, 4) document physical aquifer characteristics such as fracture frequency and orientation, 5) provide access for geophysical and hydrophysical logging and data collection, and 6) possibly provide long-term monitoring wells. The role, as described in this task, is to provide well sitting and general planning guidance, provide hydrologic support during the drilling and completion processes, provide video logging and thermal flow logging services, provide scientific oversight during commercial logging, perform aquifer testing, perform groundwater sampling, and conduct data analysis and 
interpretation. This task will generally provide the hydrogeologic expertise to ensure that the scientific objectives are met, by closely coordinating with the prime contractor in its role as the lead contractor to the various subcontractor companies (drillers, pump setters, etc.).

\section{Hydrogeologic Subcontractor Assumptions}

Drilling time assumptions are based on drilling time of seven days per well (1 day mobilization/demobilization, 1 day setup and drilling surface conductor, 2 days drilling to total depth, 1 day construction, 1 day development, 1 day contingency).

- This task includes drilling support, hydrologic logging, assistance with aquifer tests, sample collection, and analysis.

- Assume 3 months for the project.

- Drilling time assumptions are based on drilling time of seven days per well.

- Cellular phone usage is anticipated throughout the project.

- Travel to and from the site is assumed based on roundtrip airline from Reno, NV, to Albuquerque, NM. A rental vehicle will be used from Albuquerque, NM, to the drill site (480 miles roundtrip), and to and from a local motel, assuming 100 miles per day.

- Recovery of water levels is thought to take less than 30 days. A separate trip will be made to the site to measure the final recovered water level and to remove monitoring equipment.

\section{Hydrogeologic Subcontractor Estimate}

The estimate for the task described above, including all labor, analytical, operating, and travel expenses, is $\$ 107,117$ for one well and $\$ 234,963$ for four wells. Estimates for two and three wells were scaled using multipliers of 1.33 and 1.66, respectively, giving $\$ 142,798$ and $\$ 177,814$.

\section{Operating Subcontractor Cost Estimate}

Included in the operating category are subcontractors to perform earth moving and preparation work prior to and after drilling, and the drilling subcontractor. An independent bottom-up estimate, developed with DRI's cost estimating software, was compared to the costs estimated in the offsites environmental management baseline by SNJV.

\section{Operating Subcontractor Assumptions}

SNJV: Site preparation includes the construction of the well pads and sumps and any necessary repairs to the existing roads to allow access to the site. Three monitoring wells will be installed to a depth of $500 \mathrm{ft}$ using an approved drilling method. Well construction will be performed by the drilling subcontractor with the support of a four-person team during program execution. The well pads and sumps will be re-graded to restore the site following the groundwater testing.

DRI: Earthwork and road construction to support one to four wells. Drilling of one to four wells following the specifications shown in Figures A-1 and A-2. Two options were considered: with and without open-hole logging. The borehole was planned to be up to $560 \mathrm{ft}$ deep. Sixteen hours of well development were specified for the estimates, as well as wellhead completion and pump installation. 
Well depth and production rates of USGS test well number 1 located T23S, R30E, Sec. 34 SE1/4, NE1/4, SW1/4. Drilled and tested in August and September 1960.

Water-bearing formation: Culebra dolomite member of Rustler formation between 518 and 550 feet. Formation was test pumped for 24 hours at a rate of 100 gallons per minute.

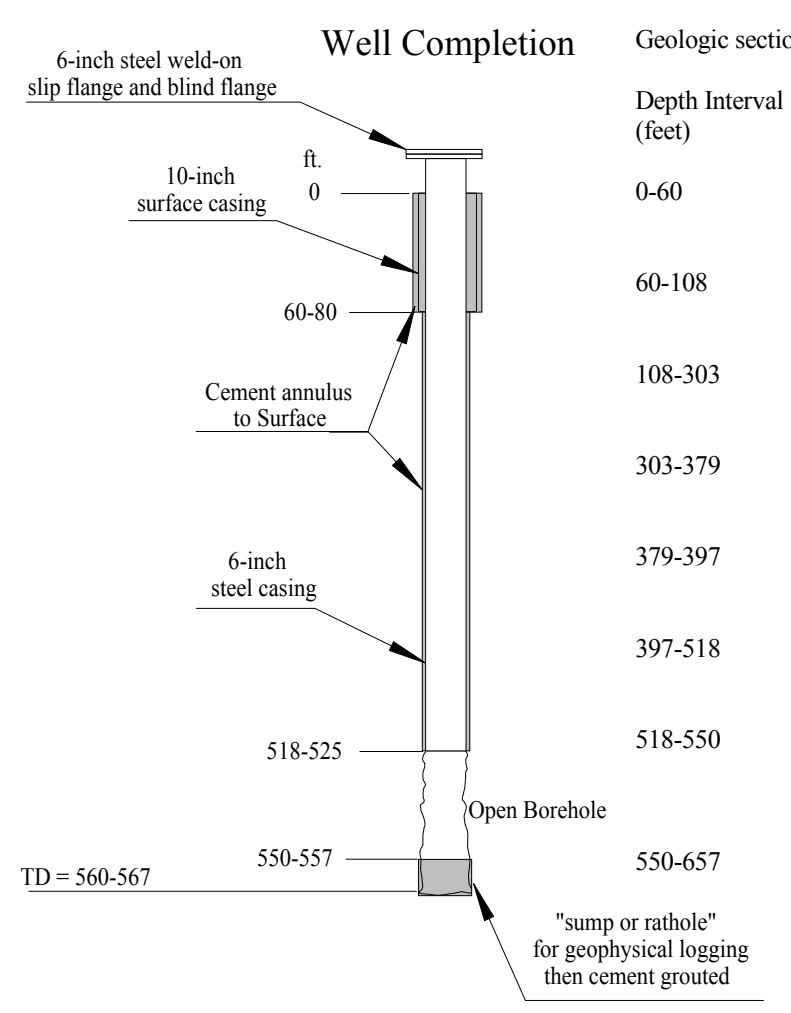

\author{
Stratigraphic Unit \\ Unconsolidated Sediments \\ Wind Blown Sand (sand and caliche) \\ Gatuna Formation \\ (Sandstone, sand, and conglomerate) \\ Pierce Canyon Redbeds \\ (Siltstone and sandstone) \\ Rustler Formation - Upper member \\ (Gypsum, anhydrite, and siltstone) \\ Rustler Formation - Magenta member \\ (Siltstone, dolomite, and anhydrite) \\ Rustler Formation - Middle Member \\ (Anhydrite and gypsum) \\ Rustler Formation \\ Culebra Dolomite Member (Target) \\ (Dolomite) \\ Rustler Formation \\ Lower member \\ (Sandstone, siltstone, and anhydrite)
}

Figure A-1. General well schematic and types of rocks likely to be encountered, based upon Gnome site well USGS-1. 


\section{Well Construction Outline}

Options

A: no open borehole logging required

$\mathrm{B}$ : open borehole logging required

1) Drill, set and cement in 10-inch surface casiing

2) A) Drill open hole to the top of the Culebra Dolomite approximately $500 \mathrm{ft}$. from grade or B) drill borehole 10 -feet beyond the bottom of the Culebra ( $560 \mathrm{ft}$.) for geophysical logging.

3) A) Set 6-inch steel casing to 520 feet and cement in to the surface.

4) A) Drill $30 \mathrm{ft}$. of open hole through the dolomite.

B) Cement bottom 10-feet of open hole

5) $16 \mathrm{hrs}$ of well development

6) Complete Well Head

7) Size pump and drop pipe. Determine after development.

8) Fit blind flange with:

Centered coupling for pump suspension

3/4" Vent hole (thread NPT)

$11 / 4 "$ Access hole (threaded NPT)

Water/ Air Tight Electric Cable Connector

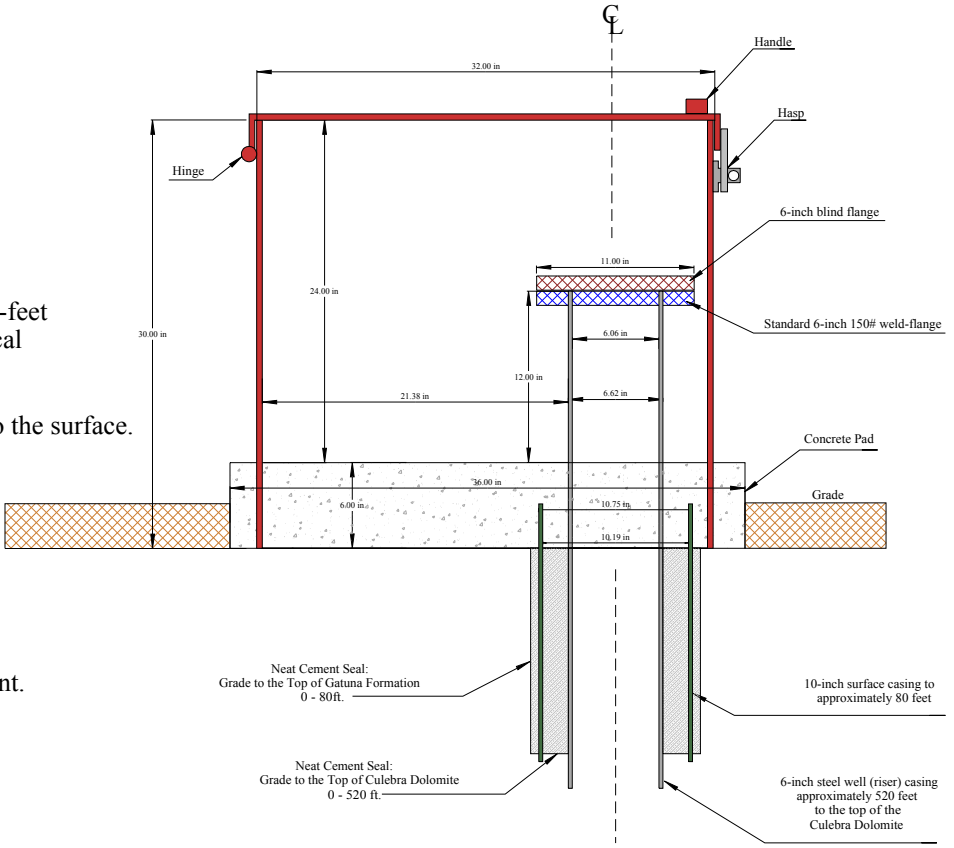

Well Head Completion

Figure A-2. Well construction specification for DRI cost estimates.

\section{Operating Subcontractor Estimate}

The subcontract costs for three wells in the SNJV-estimate are $\$ 567,475$, and it is assumed that these predominantly reflect the earth work and driller. This is assumed to relate to $\$ 189,158$ per well, though this likely somewhat underestimates the single well cost because some components (such as mobilization) are independent of number of wells drilled. DRI received one estimate for earth work and two estimates for drilling. One drilling estimate was over twice the other. The total subcontract costs in the DRI estimate varied from $\$ 110,760$ to $\$ 217,650$. Given that the estimate derived for the single well for SNJV was between the two DRI estimates, the SNJV estimate is used in the DDA. 